\title{
Homelessness Research: A Guide for Economists (and Friends)
}

\author{
August 15, 2018
}

\section{Brendan O'Flaherty}

\section{Department of Economics, Columbia University in the City of New York}

\begin{abstract}
This paper surveys research on homelessness. The emphases are on the last decade, rather than earlier; and the United States, rather than the rest of the world. The approach is more idiosyncratic than encyclopedic. The field has been converging on the conclusion that housing subsidies are the most attractive policy for reducing homelessness, but the optimal arrangement of subsidies is not obvious. Economists have much to contribute, in both theory-mechanism design and general equilibrium-and empirics. Aggregate-level studies can be used more for finding out what the effects of different policies are, and individual-level studies can be used more for assessing the costs and benefits of those effects.
\end{abstract}

\section{Acknowledgments}

I am grateful to Henry Pollakowski for suggesting this project and asking me to undertake it. Early versions of parts of this paper were part of my talk at the joint Trinity College-University of Pennsylvania conference on homelessness in May 2017. I have benefitted from helpful comments and conversations with Ann Elizabeth Montgomery, Anne L. Fletcher, Emmy Tiderington, Francesco Brindisi, Gwen Dordick, Ingrid Ellen, Julie Moschion, Rosanna Scutella, Rosanne Haggerty, Steve Metraux, and Till von Wachter. Julia Dewey Hewitt was an excellent research assistant. The errors are my own. 


\section{Table of Contents}

1. Definitions page 4

2. Individual-level studies 6
a. Housing First 7
b. Family Options 11
c. Journeys Home 13
d. Fragile Families 21
e. Case management and psychiatric services 23

3. Aggregate-level studies 24
a. Annual Homeless Assessment Report 26
b. Levels and trends 28
c. Need and generosity 30
d. Wrong person, wrong place 33
e. How does federal funding affect aggregate homelessness? 34
f. How do bed inventories affect aggregate homelessness? 39

4. Prevention 44
a. Why individual level studies should not be used to evaluate 45
b. What the studies tell us 47

5. Mysteries 50
a. New York 51
b. Los Angeles 64
c. Veterans 73
d. Unsheltered families 76
e. Race 77

6. Conclusion 79

References 74

Appendix: Robustness of veteran results 91

Figures 94 
The modern era of homelessness in the United States began almost forty years ago, on December 5, 1979, when New York State Supreme Court Justice Andrew R. Tyler ruled in favor of Robert Callahan, Clayton W. Fox, and Thomas Damian Roig, "three destitute and homeless men, in behalf of all the destitute homeless derelicts roaming the neighborhood of the Bowery." He found that "the Bowery derelicts are entitled to board and lodging," and ordered the State and City of New York to "submit a plan to provide at least 750 beds (and board for 750 men) for the helpless and hopeless men of the Bowery, in addition" to the existing facilities (Sup. Ct. N.Y. County, Cot. 18, 1979).

For close to a decade after this decision, economists published nothing about homelessness. Freeman and Hall (1987), Quigley (1990), and Honig and Filer (1993) were the seminal papers.

When I started to study homelessness in the early 1990s, it took me about half an hour to get up to speed on the economics literature. Economists who come to the subject today don't have the same luxury (and today New York City shelters close to 60,000 people a night, compared with under 2,000 when Justice Tyler rendered his decision). The purpose of this essay is to make it a little easier for someone starting to work on homelessness today to accomplish what I did in half an hour in the early 1990s.

I will summarize some of the major findings, describe some of the useful data sets, and mainly look at open questions and how they could be addressed. The emphasis will be on more recent papers ${ }^{1}$, and on the United States (with some references to Australia, since that country has some of the best

\footnotetext{
${ }^{1}$ Earlier reviews of research are in O'Flaherty (1996 and 2011).
} 
data sets and has been the source of the some of the most interesting papers in the past few years). The approach will be closer to idiosyncratic than encyclopedic.

The first section looks at definitions, the second at individual-level studies, and the third, at aggregate-level studies. Section 4 is about prevention, since both individual-level and aggregate-level studies have been done on this topic. The final section concentrates on open questions: the stunning rises of homelessness this decade in New York City and Los Angeles County, the large falls in homelessness among veterans, and the continuing question of why modern homelessness is so heavily concentrated on African Americans.

\section{Definitions}

In the $20^{\text {th }}$ century, researchers disagreed a lot about how to define homelessness. The controversy was largely a waste of energy, because there was little or no information that could help determine which definitions would be most useful. Today, controversy over definitions has subsided, but not disappeared, and several different definitions coexist peaceably, if not amicably.

The main tool for understanding different definitions is the ETHOS typology (European Typology on Homelessness and Housing Exclusion) that has been published by the European Federation of National Organizations Working with the Homeless (2005) - better known by its acronym FEANTSA. While sometimes used more prescriptively, ETHOS is a menu from which users can pick their preferred definition. ETHOS lists 13 conditions in order, from "people living rough," to "people living in extreme overcrowding." The United States Department of Housing and Urban Development (HUD) and most USbased researchers use conditions 1, 2, and 3 ("people living rough," "people in emergency accommodation," and "people in accommodation for the homeless") while most other developed countries add more conditions, especially conditions 8 ("people living in insecure accommodation") and 
11 ("people living in temporary/non-conventional structures"). ${ }^{2}$ But researchers who make international comparisons, as well as those who write for international audiences, have become adept at making comparisons.

In this paper, I will use the HUD definition unless otherwise indicated. When the differences are important, I will talk about the "American" definition (ETHOS 1, 2, and 3) or the "European" or “Australian" definition (ETHOS 1, 2, 3, 8, and 11).

More consensus has emerged on the temporal dimensions of homelessness. The headline number everywhere is point prevalence. In the $20^{\text {th }}$ century, incidence was often used, especially by advocates, but it is much less used now. Temporal issues have not disappeared entirely, thoughprogram operators treat short breaks between spells of sheltered homelessness in different ways and often continue to count people as homeless in the first several weeks after leaving a shelter. Many homeless people cycle into and out of shelters fairly rapidly, and the treatment of short spells (or short uncompleted spells) away from a shelter can often affect point prevalence counts noticeably. These enumeration issues are often hidden and rarely discussed.

Ironically, we have tools now that can say something about how useful various definitions and temporal conventions might be, but we don't use them. Longitudinal data sets like Journeys Home and Fragile Families, which we discuss in section 2 below, can help tell us what the impact of different events on the people who experience them is, and this impact can guide our assessment of what we want to measure. If, for instance, these data sets show that a month of couch-surfing had long-term deleterious effects on an individual's employment and health, then even die-hard users of the American definition would probably be swayed to start using the European definition. Conversely, Europeans might start

\footnotetext{
${ }^{2}$ The Australian Bureau of Statistics adds 13, "extreme overcrowding, but none of the Australian research cited in this paper uses that definition.
} 
counting like Americans if the data were to show that a month of couch-surfing was little different in consequences, short-term or long, from a month living alone in an apartment with a lease.

At least one paper, Johnson and Scutella (2018), makes progress on this question. They look at psychological distress, and find that it peaks on entering and leaving homelessness, and subsides in between. This paper is thus an argument that researchers should pay attention to the incidence of homelessness, not its point prevalence. This is a result about a single dataset and a single dimension of well-being, and so is very far from being a compelling argument to tear down the enumeration systems it has taken decades to construct. But more papers like this would allow us to think seriously about whether our current conventions are obscuring important information.

2. Individual-level studies

By individual-level studies I mean studies where the observations are individual people or individual households. These are the predominant kind of study in the homelessness literature, especially the literature outside economics.

The goal of these studies is usually to understand variation between individuals in homeless experience. On the other hand, policy as I understand it is about affecting variation in homeless experience between different populations (real or counterfactual), and so as an economist I used to be skeptical about the value of individual-level models.

What is the value? The primary value of these studies is to service deliverers, members of the helping professions like social work and medicine, who have a fiduciary duty to the people whom they see. These studies should inform those interactions. When I go to see a doctor about the flu, I expect her to treat me in the way that's best for me, even if she ends up making me feel well enough to go to 
work and spread the disease to my co-subway-riders, co-workers and students. Her concern is not minimizing the incidence of flu. I wouldn't go to a doctor whose primary allegiance was to the general well-being of the world. So while individual-level studies do not directly answer the questions economists are most interested in, they answer the questions that members of other professions ask.

Another value in these studies is in understanding the results of aggregate studies. For instance, Goodman et al.'s (2016) aggregate-level study of the Homebase prevention program in New York City showed that the program reduced aggregate shelter entries, and no individual-level study could have measured this outcome. But only the individual-level randomized controlled trial (RCT; Rolston et al. 2013) could tell us what proportion of Homebase participants would have been homeless without it, and what proportion of Homebase participants became homeless anyway.

Because they elucidate mechanics. Individual-level studies can sometimes help us decide when aggregate-level studies are not worth doing. Consider, for instance, a mental health or substance abuse intervention that was shown not to help its treatment group reduce the amount of time it spent homeless, relative to the control group. Since treatment is the only plausible avenue through which this intervention could reduce aggregate homelessness, if we know that this intervention does not work on the individual-level, we can be pretty sure it does not work on the aggregate level either.

Finally, individual-level studies can help us understand how homelessness affects homeless people, and more important, how different dimensions of homelessness affects them. This information is needed for any serious cost-benefit analysis.

Some of the most spectacular results in the homelessness literature have come from RCTs that many economists have not heard about, and many new data sets have become available, some connected with RCTs and some not.

\section{a. Housing First}


Housing First is an intervention for homeless people with severe disabling conditions that combines four elements: "(1) program philosophy and practice values emphasizing consumer choice; (2) community based mobile support services; and (3) permanent scatter-site housing. . . Because [Housing First] does not require psychiatric treatment or sobriety as a precondition for attaining housing, the model includes a fourth component, harm reduction, so that support services can help reduce the risks associated with psychiatric or addiction-related behavior" (Padgett et al., 2016, p. 3).

Housing First reverses the traditional "continuum of care" approach to homeless people with psychiatric or addiction-related conditions: instead of providing treatment first and subsidizing apartments for them only after they have succeeded in treatment, Housing First provides apartments first; treatment is voluntary after that. Sam Tsemberis, a psychologist, developed the original Housing First program in New York City in 1992: after many years of trying to persuade street-dwellers to go to shelters and psychiatric hospitals and accept services, he "started taking homeless people at their word [w] hen they insisted that what they really needed was a place to live, not a shelter or a hospital ward ..." (Padgett et al., p. viii).

Since then, the Housing First intervention has spread rapidly throughout the world (although not every program that calls itself "Housing First" is a faithful reproduction). ${ }^{3}$ It is the dominant model for dealing with chronic homelessness today. A major reason why Housing First has spread so widely is a series of RCTs that have shown Housing First performs better than treatment-as-usual on a number of dimensions. These RCTs randomize a group of people with severe problems (sometimes homeless, sometimes about to be discharged from a hospital with no place to go) either to Housing First or

\footnotetext{
${ }^{3} 3$ There are some definitional issues. By "Housing First" here I am referring to the application of this philosophy to permanent supportive housing for people with serious disabling conditions. "Housing first" may also apply to a more general approach of attending to housing issues quickly with any population and any type of housing resource. So rapid rehousing is sometimes referred to as part of housing first. I will not be using the term in this wider sense.
} 
standard treatment; they are followed for varying periods, and the outcomes for the two groups compared.

One systematic review found that in 11 of 12 RCTs, Housing First produced greater housing retention than treatment-as-usual (Kertesz and Johnson, 2017, p. 223). The differences were often huge: in a Canadian multi-site study with 1198 participants, the treatment group were housed 63-77 percent of the time in the two years following randomization, while the control group were housed only 24-39 percent of the time (Stergiopoulos et al., 2015).

Whether Housing First improves participants' health and functioning is more controversial. Some studies find positive effects-for instance, in control of HIV (Buchanan et al., 2009), alcohol use (Kirst et al., 2015), and community functioning and well-being (O'Campo et al., 2016). But many studies find no significant effect (Kertesz and Johnson 2017). But perhaps the most surprising finding is that Housing First performs no worse as treatment than programs that typically prioritize treatment.

(Claims have also been made that Housing First saves governments money by reducing service use by participants. Not all studies that try to estimate the change in government expenditure find this result, but some do (Kertesz and Johnson 2017). Whatever answer these studies give, they are invariably poorly framed. First, they use average cost rather than marginal cost, a difference that is especially important for hospitals, where most of the savings are said to accrue. Second, as cost-benefit analyses, they leave out the most important benefits of these programs-those that accrue to the participants and their families. One would never try to evaluate a fire department or an educational intervention in these terms. This approach to evaluation makes sense only if the purpose of programs for poor people is to maximize the after-tax income of richer people.)

What has been missing in studies of Housing First are estimates of aggregate impact: does operating a Housing First program actually reduce the total amount of homelessness in a community? If 
a person is already chronically homeless, enrolling him or her in Housing First is an excellent way to reduce his or her expected remaining time homeless, and possibly improve his or her functioning in other dimensions. But will the availability of Housing First cause other people to act differently in a way that offsets the direct effects on participants? Will it cause people who are already chronically homeless or on the brink of it to reduce their efforts to reconcile with family or find unsubsidized housing on their own, or will it induce program operators to reduce their efforts to help such people, or will it induce landlords to raise rents because they have fewer vacancies and a reliable rent payer in the Housing First program? We do not know.

The long run impact on homelessness that results from addition of a given stock of Housing First units is almost certainly less than the number of Housing First units, even without any behavioral variation. This is a simple mathematical implication of the probable fact that people leave Housing First at a slower rate than they would leave homelessness.

Consider a simple world where people enter homelessness at rate e per unit time, and leave it at rate $\mathrm{x}$ per unit time per person homeless. Then steady state homelessness is $\mathrm{H}=\mathrm{e} / \mathrm{x}$. Introduce permanent increase of $\mathrm{P}$ Housing First beds at time 0 . Assume people leave Housing First beds at rate $y$ per unit time per person, and none of them return to homelessness. Also assume $y<x$.

Then homeless population $\mathrm{H}(\mathrm{t})$ falls to $[\mathrm{e} / \mathrm{x}-\mathrm{P}]$ at time zero and then evolves according to the equation

$$
H(t)=\left[\frac{e}{x}-\frac{y}{x} P\right]-\left[1-\frac{y}{x}\right] P e^{-x t}, t \geq 0
$$

Since $y<x$, homelessness is increasing after time 0 and the rate of increase depends positively on the size of the stock P of PSH beds (and negatively on the time since they were started). The greater the stock of $\mathrm{PSH}$, the faster homelessness grows, except at time 0 . The long run decrease in homelessness is 


$$
\frac{y}{x} P<P
$$

If some people left Housing First to return to homelessness, as seems to be the case in the Canadian RCT we discussed, the decrease in homelessness would be even smaller. ${ }^{4}$

\section{b. Family Options Study}

The Family Options Study (Gubits et al., 2016) was a large RCT that Abt Associates and Vanderbilt University conducted with HUD funding. The study focused on homeless families with children; in total, 2282 families were enrolled into the study from emergency shelters in twelve sites across the United States between September 2010 and January 2012. The study was designed to measure the relative impacts of various housing and services interventions for homeless families by comparing the outcomes of families who were randomly assigned to different interventions, including: 1) subsidy-only (a permanent housing subsidy, usually a Housing Choice Voucher, and no supportive services); 2) project-based transitional housing ("temporary housing for up to 24 months with an intensive package of supportive services offered on-site"); 3) rapid re-housing (temporary rental assistance for up to 18 months with limited services); or 4) usual care (in this case, usual care means leaving families to find their way out of shelter without priority access to a program that would provide them with a place to live.) Families were followed for approximately three years, with primary data collection occurring at three separate times: baseline and random assignment, 20-months after random assignment, and 37-months after random assignment.

\footnotetext{
${ }^{4}$ The Moving On initiative (Coalition for Supportive Housing 2015) is a program designed to increase $y$ and so reduce aggregate homelessness by allowing PSH residents who have stabilized and no longer need intensive services to move their housing subsidies with them to independent units. Whether it accomplishes the goal of faster exits from homelessness depends on whether the housing subsidies or the supportive services are the binding constraint on the movement of people into supportive housing.
} 
For the three active interventions, assignment meant priority access to the intervention; families were not forced to accept the assignment, nor were families prevented from accessing interventions to which they were not assigned. As a result of this design feature, over the 37 months of observation, many families received interventions for which they did not have priority access, and some families who had priority access to an intervention did not receive it. This disparity was especially great for transitional housing: only 53 percent of the families with priority access received this treatment. Because not all families could have been randomized into every treatment-either because they were not eligible or because the treatment was not available at their site-calculating treatment-on-thetreated effects was not feasible. Instead, the study results are presented as intent-to-treat estimates, even though treatment-on-the-treated estimates would have shown much larger differences.

The headline finding from the Family Options Study was that the subsidy-only intervention provided much greater housing stability than usual care or either of the other two active interventions. Families randomized into priority access for subsidy-only were less likely to become homeless again and moved less often. The housing stability advantage lessened as time passed, but largely because more and more families without priority access received housing choice vouchers and public housing apartments. On other domains, subsidized housing did no worse than usual care and other treatments, but better than transitional housing in the domains of family preservation, child well-being, and food security (Gubits et al., 2017, exhibit ES7). It also did better than usual care in reducing psychological distress, substance abuse, and intimate partner violence. These improvements in family well-being probably have long-lasting benefits for children. Over 32 months, the direct undiscounted government cost of subsidized housing was higher than usual care or transitional housing, but not by a lot.

Like the Housing First RCTs, the Family Options Study does not tell us anything about whether any of these treatments reduce or increase aggregate homelessness. They start with people who are already homeless, and so cannot tell us whether anticipation of the intervention can in any way alter the 
number of people who are "already homeless." That is obviously a reason why the implicit policy recommendation of permanent housing subsidies would have to be tested with aggregate data. Less obviously, transitional housing seems to be dominated by rapid rehousing in the Family Options Study (transitional housing costs more than rapid rehousing, produces no better results, and families dislike it) but it could be a useful component in second-best screening schemes (see O'Flaherty, 2009 or O'Flaherty, et al., 2018b), or in making shelter stays unappealing.

The major lacuna in all of these RCTs about ending individual homelessness is a study of simply giving money rather than housing. ${ }^{5}$ Every step away from paternalism seems to result in better outcomes, and so why not take the next step? I have very weak priors about how such an experiment would turn out, but it would probably provide a useful benchmark against which other interventions could be assessed. Do housing subsidies work well because they are housing, or because they are subsidies?

Some insight about what an intervention that delivered plain cash would do can be gained from experiments that enhanced Social Security benefit receipt among homeless veterans. In that experiment, veterans at VA homeless sites who received extra help in applying for benefits had higher income, better quality of life, and marginally fewer days homeless. They spent significantly more on tobacco products, but not on alcohol or drugs (Rosenheck, 2010, pp. 28-30).

\section{c. Journeys Home}

Journeys Home is a longitudinal data set that follows 1,682 Australians for 2.5 years, beginning in 2011. It tried to gather a great deal of information from them every six months, and to a large extent

\footnotetext{
${ }^{5}$ Washington DC, with HUD support, is now piloting a program called the Flexible Rent Subsidy Program, which provides families with a subsidy of $\$ 7,200$ a year for four years, which they can spend on anything they want, as long as they document that the rent has been paid (District of Columbia 2018). But no RCT is planned. I thank Anne L. Fletcher for informing me about this program.
} 
succeeded; attrition was small. Unlike the data sets derived from the Housing First and Family Options Study RCTs, membership in the Journeys Home panel was not restricted to people who were homeless at the outset, and so researchers can follow the lives of people who might have become homeless but did not, as well as the lives of those who did. Around three-quarters of Journeys Home respondents were not homeless at the first interview (Scutella et al. 2012). The housing information is detailed enough that different definitions of homelessness can be used.

The sample was drawn from the records of Centrelink, Australia's income maintenance agency. Virtually every homeless person receives payments from Centrelink, as well as about a quarter of the rest of the population. Participants were selected as either homeless or at high risk of becoming homeless at baseline. Describing what the sample is representative of is quite hard ("very disadvantaged income support recipients" is a good summary, following Moschion 2017), but the same is true of any panel, except at baseline.

Journeys Home has already been used in several papers that have answered old questions that had never been approached satisfactorily before, raised some new questions that had been impossible to think about before, and provided useful advice to program operators and policy makers.

I have already alluded to how Johnson and Scutella's (2018) study of psychological distress should inform decisions about the temporal dimensions of how homelessness is measured. Before this paper, researchers knew that in a cross-section, homeless people were more distressed than others, but did not know whether homelessness caused that distress, or people who were more distressed for some other reason tended to become homeless. ${ }^{6}$ Johnson and Scutella reduce these problems by following

\footnotetext{
${ }^{6}$ Useful studies of how psychological distress evolves over time can, and probably should, be done with Family Options Study data, essentially reproducing Johnson and Scutella's equations. But since everyone in the Family Options Study is homeless at baseline, a study like this could tell us nothing about whether participants experienced similar levels of distress before they first became homeless, or whether they differed from people who did not become homeless. The Family Options Study also has fewer waves, and more time between waves. Psychological distress is measured only at baseline, 20 months, and 37 months.
} 
people over time, and by using person-specific fixed effects to remove persistent characteristics and dispositions. They also control for many time-varying conditions.

A positive coefficient on entering homelessness, then, would almost indicate that homelessness caused an increase in psychological distress, but not quite. It could be the case that homelessness was precipitated by some event that also caused psychological distress. But since Journeys Home controls for many events that could precipitate homelessness-job losses, relationship break-ups, and health shocks, for instance-this threat to identification may not be very large. Preventing homelessness without reversing or counteracting the unobserved event that precipitated it might also be impossible, and so in practical terms the unobserved event and becoming homeless might be the same thing.

Johnson and Scutella follow men and women separately, and looks at both the American and Australian versions of homelessness-so there are four analyses in all. For men, psychological distress rises on entering American homelessness (which they call 'literal') but not Australian homelessness (which they call 'cultural'). Long periods of Australian homelessness raise distress, but long periods of American homelessness do not. Leaving homelessness of either kind raises psychological distress. For women, housing market transitions of any kind seem to have no significant effects (except for having been homeless--Australian sense--for between six months and a year, which reduces distress). For men, incidence might be the right measure for homelessness, but for women, prevalence might be.

Johnson and Scutella's data might also be used to shed some light on whether American or Australian homelessness is a more useful measure. In that case, since American homelessness is a subset of Australian, the question might be whether American homelessness and Australian-but-notAmerican homelessness were equally distressing. Johnson and Scutella do not answer this question, but a cursory look at their table 2 suggests that the answer will probably be that equality cannot be rejected. 
These results also have practical applications, beyond the somewhat metaphysical question of how to define homelessness. Homelessness policies and programs can devote resources either to preventing homelessness or trying to reduce the length of homeless spells once they begin. The Johnson-Scutella results are an argument to concentrate on prevention for men. Thus, it would be worthwhile to repeat this analysis for other kinds of harms that could result from homelessness, like poor physical health, loss of jobs and relationships, other dimensions of mental health, loss of friends, and so on.

Indeed, studies in these other domains may give stronger policy recommendations than any study on psychological distress. This is because the fall in psychological distress for men that appears to occur with greater time homeless may be due to habituation, and reductions in distress for this reason may have ethically ambiguous interpretations. Sen (2009, pp. 282-283, 284) writes: "The utilitarian calculus based on happiness ... can be deeply unfair to those who are persistently deprived, since our mental make-up and desires tend to adjust to circumstances, particularly to make life bearable in adverse situations. It is through 'coming to terms' with one's hopeless predicament that life is made somewhat bearable by the traditional underdogs. The hopelessly deprived people ... may train themselves to take pleasure in small mercies. ... To overlook the intensity of their disadvantage merely because of their ability to build a little joy in their lives is hardly a good way of achieving an adequate understanding of the demands of social justice."

On the other hand, declining distress over time does not necessarily signal habituation, at least of the type that should be ignored for ethical analysis. Consider tooth removal. Absent analgesia, a person who has a tooth removed is likely to feel great pain in the days immediately following the removal, but that pain will gradually abate with time. In that sense, there is habituation, as the body heals itself. But most people would find nothing ethically abhorrent with a policy recommendation that strong analgesics be supplied to people who have just recently had teeth removed, but not to people 
what had teeth removed a decade ago. Whether the habituation that occurs with homeless men is more like the habituation to tooth removal or the habituation to lower caste status is an important question to which I have no answer. Approaching it will probably require both ethical and empirical inquiries.

Several other papers have also looked at old questions with new data. McVicar et al. (2015) revisits the old question of whether substance abuse causes homelessness or vice versa. During the $20^{\text {th }}$ century, enormous energy was devoted to trying to figure out the direction of causality; energy is not a good substitute for data. Temporal priority can say a lot about this matter, and longitudinal data can detect temporal priority.

McVicar et al. follow a strategy like that of Johnson and Scutella, regressing different measures of substance abuse on different measures of lagged homelessness (and contemporaneous), along with time-varying controls and person-specific fixed effects. Then they run similar regressions in the opposite direction, with homelessness as the dependent variable and substance abuse as the independent variable. For the most part, they do not find significant results, with one exception. Heavy alcohol use in one period leads to homelessness (either American or Australian, but Australian more so than American) in the next period (six months later). With this exception, their explanation for the observed correlation between substance abuse and homelessness is that the same condition, both observed and unobserved, cause both.

This result explains and confirms the results of the Housing First RCTs and of the Family Options Study. Because substance abuse for the most part does not cause homelessness, treatment of substance abuse is neither necessary nor sufficient for ending homelessness. Conversely, interventions narrowly focused on ending homelessness will do little to alleviate substance abuse. It is nice to see studies with divergent methods and settings converging to a single message. 
In a similar paper, Johnson and Moschion (2018) examine the effect of incarceration, also using individual fixed effects. Incarceration raises the probability of staying in a boarding home or with friends 6-17 months after release, but does not affect American homelessness. (Incarceration in the US may have different effects from incarceration in Australia, of course.) The homelessness also seems to have little effect on employment (Swami 2018.)

On the larger project of assessing the harms of various types and durations of homelessness, their conclusion is basically negative: neither American nor Australian homelessness causes substance abuse, and so substance abuse gives no reason for using one variety or the other. McVicar et al. did not look for effects of different durations of homelessness as Johnson and Scutella did, and so their paper gives no guidance on incidence versus prevalence, or prevention versus shortening. Adding homeless duration measures as independent variables might have found some significant effects, and so it is possible (but not highly likely) that a re-analysis would turn up something useful for definitions or policy.

Herault and Ribar (2017) also estimate the effect of homelessness on food insecurity. They find that for men, but not for women, being culturally homeless increases the probability of being food insecure contemporaneously and in the future. The paper does not use different definitions or durations of homelessness, and so lacks some of the direct policy applicability of Johnson and Scutella or McVicar et al., but makes an important methodological innovation: it finds an instrument for (cultural) homelessness. That instrument is being on a waiting list for public housing. But it is only one instrument, and so can be used for only one endogenous variable.

Thus, Journeys Home is beginning to give policy makers information that they could use to assess the consequences of their actions on the well-being of homeless people and people at risk of homelessness. The progress has been slow (and policy-makers do not seem to be clamoring to acquire this information and be guided by it), but a great deal of data remains to be analyzed. 
Several Journeys Home papers have also taken the more traditional approach of treating homelessness as a dependent variable. Cobb-Clark et al. (2016) is probably the best study yet on the duration of homeless spells. Journeys Home has many advantages over other data sets for this purpose: it's big, it includes unsheltered as well as sheltered experience, it includes multiple spells for some people, it does not rely on retrospection to date the beginning of spells, and it has many covariates, both time-varying and time-invariant. Cobb-Clark et al. approach the data as labor economists, and try to separate duration dependence from heterogeneity, both observed and unobserved. They find some covariates that influence duration, as most studies do, and they also find heterogeneity from unobserved characteristics. Correcting for these, they find that the hazard rate for ending a spell of homelessness is inverse-U-shaped, rising and then falling over time.

This is the result that one would expect if homelessness is, in fact, a "journey home." Consider a particle making a journey from one point to another, a finite distance away. The particle is buffeted by random shocks on this journey. For short periods of time, the hazard rate for arrival will be low and rising, because, even with the best of luck, it will take some time for the particle to arrive at its destination. But the hazard rate does not keep rising forever: if a long time has elapsed and the particle still has not arrived, it has probably been buffeted far from its course, and its arrival hazard at any moment is very low (and it may never arrive). As time goes on the probability that something very bad has happened rises, and so the arrival hazard rate keeps falling. (For a rigorous demonstration for Brownian motion with drift, see O'Flaherty, 2012.) This is true regardless of whether the shocks are on average harmful (homelessness is scarring) or helpful (homelessness aids recovery).

Diette and Ribar (2018) look at the compound outcome of homelessness (approximately cultural) and violence. Both men and women in the Journeys Home sample experience violence at high rates, and both violence and housing instability in one period lead to violence and housing instability six months later, for both men and women. But for women, violence and housing instability appear to be 
independent phenomena, holding many covariates constant: violence in one period does not predict homelessness in the next, or vice versa. This contradicts the traditional picture of violence as a cause of future homelessness for women, although it is no doubt a correlate. For men they found some crossover effects, but they were small.

Finally, two papers by O'Flaherty, Scutella, and Tseng (2018a, 2018b) try to answer the practical question of how program operators can get insight into who is more or less likely to enter or exit homelessness. In general, there are two ways a program operator can assign people to different services: she can use the centralized approach and ask them questions and then tell them what to do; or she can use the decentralized approach and give them incentives and let them choose. Homelessness research to date has concentrated on the centralized approach, often not even recognizing the decentralized approach as a viable option. But homeless practice has been much more open-minded than research. For instance, soup kitchens are designed to operate without questions and commands because they are unattractive as places to eat for people whom program operators do not want eating there.

The argument for decentralized systems is that sometimes participants have relevant private information about themselves that program operators could not credibly recover from them with questions, if the participants knew that their answers would be used to determine which services they would receive. The empirical question that both these papers try to answer is how much private information participants have, relative to the public information that program operators could discover by asking them questions. Journeys Home contains a great many questions that program operators could never expect honest answers from if they were consequential (for instance, "how likely are you to be living here in the three months?"), but for which Journeys Home could get informative answers 
because it was not consequential for the participants. ${ }^{7}$ By seeing how much better homeless transitions can be predicted with the private information that participants have shared with Journeys Home, we can find what scope there is for decentralized systems to improve on centralized systems.

Journeys Home participants seem to have a lot of relevant private information, and these papers outline mechanisms that could be designed to take advantage of that. Thus, Journeys Home allows mechanism design problems to be considered empirically for homelessness for the first time. No other data set yet has been as useful for this purpose.

\section{d. Fragile Families and Child Wellbeing Study}

The Fragile Families and Child Wellbeing Study is another longitudinal study. It followed disadvantaged families with young children for fifteen years in 20 US cities. The sample was drawn from births in selected hospitals in those cities between 1998 and 2000, and includes an over-sample of nonmarital births. Baseline interviews with the mothers were conducted in the hospital. The study also follows fathers. Follow-up interviews were conducted at 1, 3, 5, 9 and 15 years. Attrition was low and extensive information was collected at each wave. Most work has been done through year 5.

The major differences with Journeys Home, aside from time and place, is that Fragile Families was not designed to learn about homelessness, and concentrates on families. Time between interviews is also longer. But Fragile Families does include a substantial number of homeless spells, both American and Australian, and a number of papers have used the data.

The major weakness is that its only measurement of homelessness is whether the family was homeless (conventional US measure) for at least one day in the year before the interview. This variable is particularly inappropriate for studies that use homelessness as an independent variable. Obviously it

\footnotetext{
${ }^{7}$ For these papers, the criterion for Journeys Home questions is that the answers be informative and hence predictive of a homeless transition, not that they be true.
} 
precludes studies like that of Johnson and Scutella that look at the effects of varying durations of homelessness. Moreover, in studies without an instrument for homelessness, the homelessness variable becomes a proxy for all the time-varying conditions that were correlated with homeless entry, but which do not continue to the date of interview. Fragile Families really cannot tell us much about the harms of homelessness.

Fragile Families is more useful for studies with homelessness as a dependent variable, with the understanding that many of the spells observed will be short. Two well-identified studies use Fragile Families to find individual-level causes of homelessness.

Curtis et al. (2013) examine what happens to families of children born with severe health conditions. They link the Fragile Families births to medical information and find children who were born with severe health conditions that doctors believe are not related to maternal behavior and may thus be treated as random. At three years, these families are considerably more likely to have been homeless, holding many other covariates constant. The effect is much larger in cities with tighter housing markets. Curtis et al. (2010) follow a similar strategy for a broader range of housing outcomes. These two papers link individual-level observations and aggregate conditions in an interesting way.

Pilkauskas and Michelman (2018) look at the effect of changes in state and federal Earned Income Tax Credit (EITC) rules. They used all waves of Fragile Families. Their key independent variable for each family is the average EITC benefit a single mother with the same size family in the same state and year would receive, where the average is taken over all single mothers in the Fragile Families data set that year. Increases in average EITC payment reduce doubling up, but not homelessness. Making the EITC more generous does not appear to be a good strategy for reducing family homelessness.

(Why might this be? Perhaps many of the families at risk of homelessness have too little earned income to be affected by the average, or they are too distracted by other problems to file for EITC. 
Taking the $10^{\text {th }}$ or $20^{\text {th }}$ percentile of the EITC benefits in a state-year might be a more interesting strategy to find out about homelessness than taking the average. Alternatively, since raising the EITC raises housing consumption by poor people in general, raising EITC may raise rents and squeeze families who for some reason gain less from EITC than others.)

\section{e. Case management and psychiatric services}

Rosenheck (2010) reviews several experiments that tried to assess the results of providing case management and psychiatric services, including substance abuse treatment, to homeless single adults with mental illness or alcohol or drug problems.

An experiment in 1992 compared three interventions for homeless veterans: "section 8" housing vouchers (the precursor of Housing Choice) with intensive case management, intensive case management without housing subsidies, and standard time-limited case management. After three years, the group with the combined vouchers and intensive case management had better outcomes on all measures: fewer days homeless, more days housed, stronger therapeutic alliance ("a measure of treatment satisfaction" (p. 21)), and better substance use outcomes. Outcomes for intensive case management without housing subsidies were little different from those with usual care.

The San Diego McKinney Demonstration "used a two-by-two design crossing access to housing vouchers by two levels, high intensity or low, of case management" (p. 23). Intensity of case management made no difference to housing outcomes, but housing vouchers led to better housing outcomes. Unfortunately, the difference in intensity of case management between high and low turned out to be quite small. 
Other studies that look at particular kinds of non-housing treatments find modest benefits, but do not compare these benefits to those of receiving housing subsidies. In a St. Louis experiment on different intensities of case management where no participants received housing subsidies, there were no significant differences in housing outcomes. But in a Baltimore experiment where all participants received housing subsidies, those who also received a treatment called Assertive Community Treatment had better housing outcomes, and in New York in a similar experiment, participants who received Critical Time Intervention also had better housing outcomes. These treatments, however, are fairly expensive.

Finally, programs that seek to enhance the employment prospects of homeless veterans also produce modest positive effects.

Thus these studies tend to temper the findings of the later studies that only housing subsidies matter. When combined with housing subsidies, some non-housing interventions can reduce individual homelessness somewhat, and improve some outcomes in other domains. But they are neither cheap nor powerful. The studies in this section indicate that no one has yet found a similarly powerful intervention that does not rely on housing subsidies.

Individual-level studies generally indicate that wise homelessness policy is mainly going to be about arranging housing subsidies.

\section{Aggregate-level studies}

As an economist, I was not trained to have a fiduciary duty to anyone, and so aggregate models are what I care about most; I think about policies, not interventions. The important question is, When all is said and done, what reduces the number of people who are homeless (however defined), and by 
how much does it do so? Up until recently, little work had been done in this area, mainly because even mildly credible data on aggregate homelessness were unavailable, but with more and better (although not necessarily good) data, the second decade of the $21^{\text {st }}$ century has seen a proliferation of studies on aggregate homelessness. Most of them have concentrated on the effects of what they take to be policies, and so will I.

The importance of dealing with aggregates can be seen in the emerging policy discussions about eviction practices. Desmond's (2016) work called attention to evictions as a precursor to homelessness, and so delaying or preventing evictions has become a popular new intervention to reduce homelessness. For instance, Newark recently announced a program to make sure tenants facing eviction had legal representation (Yi, 2018). Collinson and Reed (2018) in the first well-identified study of the evictions, find that eviction makes New York City households more likely to become homeless and more likely to be hospitalized for mental illness, but does not affect earnings or public assistance receipt.

But economists know that an intervention like this cannot be studied in isolation. Both landlords and tenants are likely to react. Tenants may take more chances in delaying rent. Whatever tenants do, landlords may raise rents or tighten their screening standards. Tighter screening standards may result in higher vacancy rates, or may exclude potential tenants who are likely to be or become homeless.

Whether anti-eviction programs reduce or increase homelessness, then, is an open question, and one which individual-level studies cannot resolve. The comparison that must be made is between housing markets with anti-eviction programs and housing markets without them, and then only after landlords and tenants have had enough time to adjust to the new rules. Of course, the housing markets for this comparison should be chosen as-if randomly, and so doing the right study will be hard. But it is worth doing. 


\section{a. Annual Homeless Assessment Report (AHAR)}

The major innovation in the $21^{\text {st }}$ century for the study of aggregate homelessness has been the Annual Homeless Assessment Report to Congress (AHAR). Congress first directed the Department of Housing and Urban Development (HUD) to develop an unduplicated count of homeless people in the fiscal year 2001 appropriations act (US HUD, 2007, p. 8). They asked both for a system of tracking homeless people and for reports on how their numbers were changing. Congress had been funding homeless programs for fifteen years, and wanted to know what the results of its funding were. Responding to this directive was hard, and the first AHAR was not produced until 2007, and the quality of its data was admittedly low. AHARs have been produced every year since then, under contracts with Abt Associates and the University of Pennsylvania.

Each AHAR consists of three data sets: a point-in-time count of sheltered and unsheltered homeless people on a night in late January, information on the characteristics of sheltered people during the year, and an inventory of beds available to shelter the homeless. Continua-of-care (CoCs) are responsible for collecting the data and funneling it to HUD; these are administrative units that receive funding from HUD for homeless programs. There are now about $400 \mathrm{CoCs}$, and they cover individual cities, counties parts of states, whole states, and consortia of any of these. For instance, New York City is a $\mathrm{CoC}$, and so is Los Angeles County, minus the cities of Glendale, Long Beach, and Pasadena.

(Henceforth when I say "Los Angeles" or "New York" without further specification, I will mean the CoCs.) CoCs are supposed to report every year, but are only required to count unsheltered people in odd years. Many, however, count unsheltered people every year. Sometimes, especially in the early days, CoCs fail 
to report. For national $\left.\right|^{8}$ purposes only a sample of CoCs are used, and those CoCs receive extra attention.

Thus the AHAR data are gathered by amateurs who are not indifferent to the outcome. To some extent the amateurism is offset by the fact that many CoCs have contracted their responsibilities to organizations, both nonprofit and profit-making, that have come to specialize in this task. I don't know of any study of these contractors.

But even when professional outside organizations supervise reporting, the point-in-time count of unsheltered homeless people in each CoC almost always relies on a loosely supervised army of amateur volunteers who traipse (or in some cases drive) through streets and parks on a night in late January. Their diligence, understanding of the process, and lack of bias are all open to question. Sometimes following instructions can be hard: for instance, the New York instructions are to stop and query everyone who is not in uniform, but even at $2 \mathrm{AM}$ there are too many people on the sidewalks in Midtown Manhattan to stop each one, and in many other locations one encounters strangers with whom one does not wish to engage at that hour. Volunteers have no authority to enter onto private property, and so most counts explicitly exclude homeless people who are staying in restaurants, parking garages, or stairwells, for instance.

Counting sheltered homeless people is pretty similar to what law enforcement agencies to in submitting information for the Uniform Crime Reports, but estimating the number of unsheltered homeless people requires more statistical sophistication than anything that law enforcement agencies are expected to do.

\footnotetext{
8 "National" for purposes of AHAR includes Puerto Rico, the US Virgin Islands, the Northern Marianas, Guam, and American Samoa.
} 
When AHAR data are dependent variables in a regression, there are two serious questionsheteroskedasticity and correlations between errors and policies of interest. If AHAR data just contained uniformly distributed noise, there would be nothing to worry about, for most purposes. But if expected errors are larger in some CoCs than others (for instance, because CoCs with a lot of unsheltered homelessness and small investments in the street count), then data from those CoCs should receive less weight. And if CoCs with some policy tend to undercount or overcount (for instance, if CoCs with a lot of transitional housing have managers who want to dramatize the seriousness of homelessness by coming in with huge counts), then the measured effect of the policy contains an unknown correlation of the policy with measurement error.

What to do about this? The obvious correction starts with collecting and using data on the methods by which CoCs took their PIT counts, not just the results of those counts. HUD already collects some of this data. Useful information would include who was responsible for the count and what was the sampling strategy for the street count. Then researchers should include data on methods as explanatory variables, possibly interacted with the independent variables of interest. Researchers could also use this information for weighted least squares strategies.

Another approach would involve looking at Australia again. In Australia, the census counts homeless people, and so plausibly the data are better. Johnson et al. (2015) have looked at the correlates of Australian homeless counts, and they are very different from the US correlates. Part of this is due to Australian definitions. It would be interesting to try to translate the Australian counts to US homelessness counts, and then try to replicate some of the US studies with Australian data.

\section{b. Levels and trends}


National data from the first few years of AHAR are regarded with skepticism, but data after that are beginning to tell a story. Starting around 2010, the number of homeless people has been falling. There is no trend before 2010 , and the quality of the data before then would not support any strong conclusions anyway. Figure 1 illustrates. The overall number of people (the point-in-time count) fell from about 637,000 in 2010 to 553,000 in 2013, a decrease of about 13 percent. Given the quality of AHAR data, this is a modest trend.

Figure 2 breaks down this trend by major categories: sheltered individuals, unsheltered individuals, sheltered families, and unsheltered families ("families" in AHAR means families that include children). All categories fell between 2010 and 2016, with the largest decrease being among unsheltered families, in both relative and absolute terms

While overall homeless population has been falling, the trend in the two largest CoCs, New York and Los Angeles, has been the opposite. Both have seen large increases, so that in 2017 the two CoCs accounted for 23 percent of homeless population (as opposed to 5.4 percent of the total population). The composition of the homeless population in these two CoCs is different: New York has a large population of sheltered families (27 percent of national sheltered family population) while Los Angeles has a large population of unsheltered individuals ( 23 percent of national unsheltered individuals in 2017). The decline in homeless population is much more substantial in the US excluding New York and Los Angeles: about 23 percent between 2010 and $2017 .^{9}$

Figure 3 compares New York and Los Angeles to the rest of the nation in each of the four major categories of homelessness. In every category, both large CoCs are moving in the opposite direction

\footnotetext{
${ }^{9}$ The rate of homelessness in the US outside New York and Los Angeles was 13.5 per 10,000 population in 2017. The rate of Amcrican homelessness in Australia in 2011, when Journeys Home was underway, was 13.1 per 10,000 (Australian Bureau of Statistics 2012). Thus Journeys Home data are not drawn from a world very different from the US outside New York and Los Angeles.
} 
from the rest of the country, except for sheltered individuals in Los Angeles. (New York claims that there are no unsheltered families, and this claim is probably approximately true.)

Homeless veterans are another category of great interest. Between 2010 and 2017, the number of homeless veterans fell from 74,000 to 40,000, a decrease of 46 percent (HUD 2018, p. 52). Sheltered population fell 39 percent, and unsheltered population fell 50 percent. Homeless veterans are concentrated in Los Angeles. In 2017, 11 percent of homeless veterans were in Los Angeles, 22 percent of unsheltered homeless veterans. What explains these trends? In particular, are there policies that caused the decline or prevented New York and Los Angeles from joining it? We do not know. In the rest of this section, I will look at several attempts to explain pieces of the decline. First, I will try to provide some theoretical basis. Then I will look at papers that use AHAR data as dependent variables. In the following section, I will look at New York, Los Angeles, veterans, and unsheltered families in more depth.

\section{c. Need and generosity}

Most homeless people, especially in cold cities, are sheltered. The number of sheltered people at any time is constrained by the availability of shelter spaces. To think about how many people are sheltered, we have to think about decisions to supply shelter space. Thinking solely about people at risk of homelessness is insufficient.

O'Flaherty (2003) proposes a way to approach the two sides that jointly determine how many people are sheltered. The basic approach is supply and demand, an idea quite familiar to economists, but with "shelter quality" playing the role of price. Shelter quality means the amalgam of aspects of shelter existence that matter to residents; not only space, light, and food, but also security, quiet, privacy, and freedom, too.

Holding opportunities outside of shelter constant, the number of people who want to stay at a shelter depends positively on a shelter's quality: the better the quality, the more people want to stay. 
Call the relationship between the quality and the number wanting to stay the "need curve." Changes like greater poverty, colder weather, or higher rents move the need curve out.

On the other side of the market, people who pay for shelters also care about quality. The higher the quality of a shelter, the more it costs per person, and so the fewer people they are willing to shelter. In a higher quality shelter, moreover, both the marginal and the average shelter resident will have more attractive outside opportunities, and so alleviation of suffering may be smaller. Thus higher quality implies less quantity. Call the relationship between quality and the number of people whom donors want to shelter the "generosity curve."

Notice that the generosity curve slopes down no matter what the market structure is. If the market is competitive, with many independent shelters in a town, then each shelter-provider has to take the prevailing quality as given, since lower quality than that will empty her shelter and higher quality will be suboptimal for her. If the market is non-competitive, the shelter provider will also contemplate for each quality the optimum quantity of shelter it will want to provide, and higher qualities will correspond to lower quantities. The monopoly shelter provider's generosity curve is different from a competitive shelter provider's, but they both slope down.

What moves generosity curves? Attitudes toward poor people and religion, obviously, but also wealth at the top of the distributions since charity is a normal good. Market structure matters, too, since the competitive curve is different from the monopolistic one. Population density may also matter: to the extent that rich people are willing to pay to avoid seeing or being confronted by poor people on the streets, they may support shelters. Federal and higher level government actions may matter too, as federal funding may crowd out local or private funding.

Equilibrium occurs where the two curves intersect: need and generosity jointly determine the quantity and quality of shelter. Figure 4 illustrates. The basic comparative statics are obvious: if the 
shelter population rises because people at risk of homelessness become needier, shelter quality will fall; if shelter population rises because people not at risk of homelessness become more generous, shelter quality will rise. A city may have a large shelter population either because it is very needy (and shelter quality is low), or because it is very generous (and shelter quality is high).

Thus a reduced form equation for shelter population that does not include a quality variable is not a good way to estimate the determinants of shelter population. It is mis-specified. The correct specification is obvious: a well-identified pair of equations, each of which includes a shelter quality variable. Exclusion restrictions should be easy, since many things affect either need or generosity but not both. To date, however, no one has used the correct specification (Early and Olsen 2002 comes closest). The problem is the measures of shelter quality are not readily available. Working on this problem should have a large payoff.

This model can be extended to some important and interesting special cases. New York City operates under a right-to-shelter system: any eligible person or family who asks for shelter must be provided adequate shelter. Massachusetts and Washington, D.C., have similar policies but only for certain classes and times. In our terms, right-to-shelter means that the generosity curve is flat at the quality of adequate shelter. See figure 5. The right to shelter was established in New York City in a series of court decisions and consent decrees starting in the late 1970s (Callahan v. Carey, Eldred v. Koch, McCain v. Koch) and there ensued two decades of litigation. As figure 5 suggests, most of that litigation was about what quality of shelter was adequate (see Main 2016 for an enlightening account). In theory, changes in shelter population in right-to-shelter jurisdictions will be due entirely to changes in need, but in fact systems are more complex.

We can also look at the unsheltered population in these terms. In the simplest approximation (but only in the simplest approximation), the outdoor world is a big shelter that operates under right-to- 
shelter rules: if you go outside, outside has to let you in. To a first approximation, quality is determined by weather (and so varies from day to day), and so is the same for everyone in a town. Figure 5 applies, although San Diego's quality is higher than Anchorage's. But there are also complications. Congestion is possible, and naturally better locations for sleeping may become congested before worse ones. This would make the generosity curve slope down for higher quantities of unsheltered homeless people.

The actions of non-homeless people can also move the generosity curve for outdoor accommodation. Deliveries of food to places where unsheltered homeless people congregate, for instance, act just like better weather. For unsheltered homeless people probably the equivalent to shelter operators are the police, who have many tools to control the quality of life on the streets. Stuart (2016) provides an ethnographic account of the ways in which the Los Angeles Police Department affects the well-being of people on the street in that city. If police become more aggressive when more people are on the street, then the generosity curve slopes down, rather than being flat. So unsheltered homelessness can be studied with the same tools that can be used for sheltered homelessness, even though quality is harder to observe.

Thus when we see the fall in homelessness between 2010 and 2017, particularly the fall outside Los Angeles and New York, we cannot jump to the happy conclusion that need has fallen too. The reason may instead be reduced generosity. The two most glaring exceptions to the downward trendthe streets of Los Angeles and the shelter of New York-are both plausibly "right to shelter operations where generosity has less scope to vary. More careful analysis is needed.

\section{d. Wrong person and wrong place}

Another specification issue that bedevils studies of aggregate homelessness is the conjunction between general conditions and person-specific conditions. This is an issue that affects the need curve. On an individual basis, homelessness is correlated with several personal conditions like poverty and 
mental illness, but the severity of the conditions that is required to trigger homelessness varies with general conditions like temperature and the price of housing. The income and health status sufficient to avoid homelessness in a cold, low-rent area like Detroit is plausibly lower than the status required to avoid homelessness in a warm, high rent area like San Diego. The finding of Curtis et al. (2013) in the individual literature supports this inference: families with births of children with severe health problems were more likely to become homeless in cities with tight housing markets. Hence aggregate regressions where, for instance, poverty rates and rent levels are both entered as linear regressors are mis-specified as need curves. See O'Flaherty (2004). Corinth and Lucas (2018) also make this point with regard to temperature.

The remedy for this problem is easier than the remedy for the need-and-generosity problem. In a high rent city, a higher proportion of poor people are likely to be homeless than in a low rent city. So regressions for aggregate homelessness should include interactions between population characteristics (proportion poor or mentally ill, for instance) and conditions that affect everyone (temperature or price of housing, for instance). This procedure has been rarely used, but it could be.

e. How does federal funding affect aggregate homelessness?

The advent of AHAR has made it much easier to run regressions that try to explain aggregate homelessness, and has made those regressions more credible. It has also allowed researchers to hone in on policy responses to homelessness. Earlier cross-section studies (which I summarized in (1996) and (2011)) also looked at a few policy variables - rent control in several papers, and subsidized housing in Early and Olsen (2002).

Raphael (2010) was probably the first published paper to use AHAR data; he found that tighter zoning regulations in a metropolitan area correlated positively with homelessness, and that this 
relationship was mediated by housing prices. ${ }^{10}$ Since then, most papers have concentrated on trying to estimate either the effects of federal funding or of the allocation of different kinds of shelter and housing resources ("bed inventory papers"). In this section, I look at the federal funding papers, and in the next section, the bed inventory papers.

At least three recent papers (Moulton 2013, Popov 2017, and Lucas 2017) have used federal funding for homeless programs to as a key independent variable. The question they ask is worthwhile: does federal funding for homeless programs reduce homelessness? I will concentrate on Popov (2016) because it has the most careful identification strategy.

Popov's instrument arises from an anomaly in the federal formula for $\mathrm{CoC}$ and Emergency Solutions Grant (ESG) funding that gives more money to CoCs with a higher proportion of housing units built before 1940. Popov shows that proportion of 1940 housing has little or no direct relationship with homelessness or poverty. It appears to be a valid instrument. Since the proportion of pre-1940 housing is fairly stable over time, and because the formulas are also stable over time, Popov claims he is observing the effects of a more-or-less permanent funding increase.

What does it mean for a $\mathrm{CoC}$ to have more funding available from these two grant programs? The two programs, while large (roughly $\$ 2.5$ billion a year around 2011, the year Popov concentrates on) are not the only source of money for homeless programs. On the federal level, the U.S. Department of Veterans Affairs has several programs to combat homelessness among veterans and their families (see section 5 below) and the HUD funds Housing Opportunities for People With AIDS (HOPWA), which in many jurisdictions serves many people at risk of homelessness. Federal funds under the Housing Choice Voucher, Low Income Housing Tax Credit, and Temporary Assistance to Needy Families programs are

\footnotetext{
${ }^{10}$ Wilde (2012) used AHAR data to ask whether CoCs that adopted Ten-Year-Plans in response to urging by the federal Interagency Council on Homelessness reduced homelessness faster; the impact was fairly small. This paper has not been published.
} 
also often used for homeless programs. State and local governments, private charities, and private individuals also provide funds for homeless activities.

For 2011 and Popov's paper, the most important source of additional funding was the Homelessness Prevention and Rapid Rehousing Program (HPRP), which funded the activities in its name. Congress appropriated $\$ 1.5$ billion for HPRP under the Obama economic stimulus program, and it ran for three years, October 2009 through September 2012. Crucial for Popov's identification strategy, HPRP funds were distributed according to the ESG formula, and so his independent variable is really the sum of ESG, CoC, and HPRP grants. His identification strategy fails unless the variable is interpreted this way.

What could CoCs do with this money? HPRP money had to be used for prevention and rapid rehousing, and since these were new activities that most CoCs were unfamiliar with, HPRP money probably did not substitute for local or other federal money (one exception is New York, which had been running a large prevention program before 2009). These activities, if at all successful, move the need curve in: at any quality fewer people want to be in shelters, because more people have conventional housing. We will see in section 4 that some prevention programs have reduced homelessness, although the Family Options Study found that families with priority access to rapid rehousing did not spend significantly less time in shelters than families assigned to usual care did (Gubits et al., 2016). I am not aware of any studies of rapid rehousing or prevention for individuals. So it is possible that HPRP moved the need curve for shelter in. It may have moved the need curve for unsheltered homelessness in, but that is less likely.

This money could also be used to increase the quantity or quality of shelter spaces. Popov's narrative concentrates on this possible use. These activities move the generosity curve for sheltered 
homeless out, and the need curve for unsheltered homeless in (provided that the equilibrium shelter quality improves).

CoC money could also be used for permanent supportive housing. Permanent supportive housing is an intervention "that combines non-time-limited affordable housing assistance with wraparound supportive services for people experiencing homelessness as well as other people with disabilities .... It looks and functions much like any other brand of housing. People living in supportive housing have a private and secure place to make their home, with the same rights and responsibilities. The difference is that they can access, at their option, services designed to build independent living and tenancy skills, assistance with integrating into the community, and connections to community-based health care, treatment, and employment services" (US Interagency Council on Homelessness, 2017). ${ }^{11}$ Housing First is a species of permanent supportive housing (although we do not know how many of the units counted as permanent supportive housing in the AHAR are Housing First).

Although permanent supportive housing can be funded with $\mathrm{CoC}$ and Emergency Solutions Grant funds, people living in permanent supportive housing are not counted as homeless. Thus an increase in permanent supportive housing beds moves the need curve for both sheltered and unsheltered homelessness in.

Finally, nothing in any of these three funding sources can be used to improve the quality of unsheltered homelessness. Hence we do not expect additional funding to move the unsheltered generosity curve.

Popov first finds that more funding increases the quantity of shelter space provided; the money is not totally substituted for local sources. Provision of transitional housing does not change, but an

\footnotetext{
${ }^{11}$ This official definition somewhat overstates the actual rights and responsibilities of people living in permanent supportive housing. In most cases, the agency running the program is the leaseholder. The USICH language is aspirational, not descriptive.
} 
additional $\$ 100,000$ in $\mathrm{CoC}$ and Emergency Solutions Grant funding raises the number of emergency shelter beds for individuals by 26 , and family members by 76 . It also raises the number of permanent supportive housing beds for individuals by 41 and for families by 5 . These results are significant.

There is a certain implausibility with these results. Using fiscal year 2011 New York City costs per night for emergency shelter implies that the beds created by $\$ 100,000$ would cost around $\$ 1.9$ million (City of New York, 2011). Using current costs of permanent supportive housing in the HUD-VASH program implies about $\$ 600,000$ a year for the increase in supportive housing. Thus, the increases in provision that Popov finds for an additional $\$ 100,000$ in federal funds cost about $\$ 2.5$ million. Even if our unit costs are off by an order of magnitude, the result costs far more than the cause. Either marginal dollars are tremendously leveraged, or something is wrong with the instrument.

Be that as it may, let us think about the implications of these changes, assuming that the funding is responsible for them, for individuals and for families.

Figures $6 \mathrm{a}$ and $6 \mathrm{~b}$ show the implications for individuals, sheltered and unsheltered respectively. More funding should decrease the unsheltered population of individuals, because of both HPRP and permanent supportive housing (PSH). The effect on sheltered individual homelessness is ambiguous: HPRP and permanent supportive housing work to decrease shelter population, but the move in the generosity curve from possibly more attractive shelters works in the opposite direction. For families, the picture is similar to the picture, figure $6 a$, for individual shelters.

Popov finds that $\$ 100,000$ in additional funding raises family emergency shelter population by 73 , individual emergency shelter population by 46 , and decreases unsheltered population by 45 . This is consistent with our expectations, given the change in beds, since more money went to CoC and Emergency Solutions Grants than to HPRP. He interprets the approximate equivalence of the gain in individual shelter population and the fall in unsheltered population as indicating that improved shelter 
quality and permanent supportive housing could seamlessly transfer people from street to shelter without attracting more people to shelters, but this interpretation neglects the possible role of HPRP. The need curve for individual shelters is not vertical: it took both permanent supportive housing and HPRP to offset the shelter quality improvement that took 45 people off the streets.

Notice that in Popov's scenario, concentrating on individuals, the number of permanent supportive housing beds goes up by 41 and the number of homeless people goes up by 1 . Does this imply that permanent supportive housing does not reduce aggregate homelessness? Of course not. The likely increase in shelter quality works to raise homeless population, and HPRP activity works to decrease it. The comparison between permanent supportive housing beds and change in homelessness does not mean much.

It is important to remember that Popov's equation is a reduced form. It can answer a question that is important in Washington: what will happen if appropriations for $\mathrm{CoC}$ grants and Emergency Solutions Grants go up by $\$ 100,000$ and appropriations for HPRP increase by $\$ 20,000$ ? This gives some indirect bounds on the structural equations, but it does not tell us much about them. The programmatic questions (like, what does permanent supportive housing do?) can be answered only by fitting a more structural model.

\section{f. How does bed inventory affect aggregate homelessness?}

Instead of using funding information as the main independent variable, another group of recent papers (Byrne et al 2013, Byrne et al. 2014, Corinth 2017) has used bed inventory information-in particular the number of permanent supportive housing beds. This strategy has the advantage that, if you are interested in programmatic questions, it cuts directly to the variables of interest. It removes the issue, for instance, of how much federal funding is used to substitute for local sources and how much 
additional funding the federal funding attracts. On the other hand, the equations are still reduced form, but they cannot even answer the Washingtonian questions.

I will concentrate on Corinth (2017) because it has an identification strategy and is the most recent. He uses panel data from the AHAR for 2007-2014, state-year fixed effects, and CoC fixed effects, as well as time-varying $\mathrm{CoC}$ controls. So he is essentially looking at within-CoC variation over time. His instruments for permanent supportive housing beds are earmarked awards from HUD (in dollars) for permanent supportive housing and for transitional housing (he also instruments for transitional housing beds). The decisions on these awards are based on information that is at least a year old, and possibly on the overall character of the $\mathrm{CoC}$ and the talents of its administrators, but these latter factors are absorbed in the CoC fixed effects.

Over a variety of different specifications, he finds that 100 permanent supportive housing beds reduce point-in-time homelessness by about 10 , with larger effects for individuals than for families, and for the unsheltered than for the sheltered. As Corinth points out, this estimate is consonant with the estimated effects of other housing interventions. Ellen and O'Flaherty (2010, p. 12, fn. 3) review preAHAR literature on somewhat targeted varieties of public housing and Housing Choice Voucher subsidies, and find that the effect on point-in-time homelessness is usually in the neighborhood of 3-7 fewer homeless households per 100 subsidized units. The work on New York, reviewed in section 5 below, finds that placing 100 homeless families into subsidized apartments reduces point-in-time shelter census by 20-40 families. But the denominator in the New York papers, families placed, is a flow, not a stock. Corinth's variable is a stock (to be consistent with Corinth, the New York studies would have to measure total number of formerly homeless families in subsidized housing, which would be a considerably larger number), and so the larger numerator for those studies is somewhat in keeping with Corinth's result. 
Why might a reduced form equation find that 100 permanent supportive housing beds decrease the point-in-time count by less than 100 ? There are many reasons.

First, permanent supportive housing shifts the need curve, and even if the curve moves in by 100 at every quality (which we will see is unlikely), the change in sheltered homelessness will be less than 100 as long as the generosity curve has a greater slope (in absolute value) than zero. Only if the generosity curve is flat would shift in the need curve of 100 reduce homelessness by 100 . Notice that in cases where the generosity curve might be approximately flat-unsheltered homelessness and the New York right-to-shelter environment-we found that housing interventions had larger effects on point-intime homelessness.

Permanent supportive housing might also have an indirect effect on the location of the generosity curve, especially for individuals. Many shelters (and encampments on the street, too) offer their residents little privacy or security from each other. A major determinant of the quality of life that an individual experiences, therefore, is the character and behavior of the other people with whom he or she shares the shelter or encampment. Some mentally ill and substance-abusing people can be unpleasant to spend time with or to sleep next to. In many cases, permanent supportive housing is supposed to target the individuals with the most severe psychiatric or substance abuse problems, and if it does so, some of the most disturbing people may be removed from shelters and encampments. This would raise the quality of shelters and encampments without additional expenditure by their sponsors and raise shelter population. The effect on unsheltered population is ambiguous: the generosity curve will rise, but the need curve will shift in because of the improved shelter quality.

(Is there any evidence of an effect like this? Yes. Many ex-offenders become homeless on leaving detention, and so one would expect that a greater volume of discharges from jails and prisons would increase New York's single adult shelter population. But it does not. Wu and O'Flaherty (2008) 
found the opposite effect, a result which was fairly robust. One plausible explanation for this correlation is that the presence of some ex-offenders makes shelters unattractive to others, and so reduces their population on net.)

Second, 100 units of permanent supportive housing stock probably shifts the need curve in by considerably less than 100. Part of the reason is the arithmetic relationship we showed in section $2 a$, on Housing First. In the long run, the flow of new entries to permanent supportive housing is less than the stock. Absent any other leakage, the reduction in point-in-time homeless population per permanent supportive housing unit is the ratio of homelessness exit hazard rate to the permanent supportive housing exit hazard rate, which is probably less than one.

There may also be behavioral effects. By giving priority to people who have been homeless longest, permanent supportive housing recruitment rewards long spells of homelessness. Some people who have been homeless a long time may pass up mediocre opportunities to be conventionally housed in the hope that continuing homelessness will result in the prize of a permanent supportive housing apartment. It is even possible, though unlikely, that a few people will be somewhat more likely to begin homeless spells because of the opportunity. Neither behavioral effect has been measured yet.

Notice that this narrative about the effects of adding permanent supportive housing beds gives a different picture of who benefits from the traditional mechanical story. The traditional narrative has only one person benefiting, the recipient (and maybe taxpayers, in the advocates' version). But in the story the data suggest, the benefits are widely disseminated among many people. Some people who would be homeless anyway are better off because their shelters are higher quality and their colleagues are better behaved. Some people who would not be homeless absent the permanent supportive housing beds are better off too, because they do not find themselves living in conventional situations so 
miserable that they are not much better than being homeless. The story the data suggest implies a more equitable distribution of benefits.

By coincidence, population-adjusted total homelessness in the US has fallen by about the same amount as population-adjusted permanent supportive housing beds have grown. Between 2010 and 2017 , homelessness fell by 3.8 per 10,000 population, and permanent supportive housing beds grew by 3.1 per 10,000 . But correlation is not causality, and the Corinth result implies that only about 0.3 per 10,000 of the fall in homelessness was due to the expansion of permanent supportive housing beds (although the 95 percent confidence interval on this estimate is fairly broad).

The source of the rest of the fall in homelessness $(3.5$ per 10,000$)$ is uncertain. The unemployment rate fell considerably over this period, and Corinth's main equation (table 8, equation IV2) implies that the fall in unemployment and lagged unemployment reduced homelessness by about 2.1 per 10,000. But this was offset by a rise in median gross rent (and lagged median gross rent) that raised homelessness by about 0.9 per $10,000 .^{12}$ That leaves 2.3 per 10,000 of the drop unexplained.

There are many possibilities for explaining the residual, about 78,000 people. I have not used Corinth's weather variables or matched changes in unemployment and rent by CoC. (Corinth makes these corrections in looking at explanations for the change in aggregate homelessness for the 2007-2014 period, but the growth in permanent supportive housing was less aggressive in this period, and the AHAR probably had greater noise.) Other possibilities include the growth of prevention and rapid rehousing, the spread of best practices through activities like the 100,000 Homes Campaign, the many new veterans' initiatives beyond supportive housing (although I show below that these initiatives

\footnotetext{
12 Median gross rent for 2017 was not available from ACS at this writing, and so I extrapolated the same percentage increase from 2016 to 2017 as from 2015 to 2016. I also used real median gross rent. I am not sure whether Corinth used nominal or real, but if he used nominal, a portion of inflation would have been picked up in the state-year fixed effects.
} 
probably do not explain much of the residual), more accurate street counts, waning volunteer enthusiasm for street counts, and the general retrenchment in state and local government activity. The residual also may be purely estimation variation.

Thus except for Raphael's early work, the recent well-identified AHAR-driven papers concentrate on only two policy variables: explicit HUD funding for homelessness and bed inventory. They find that these variables do not have big effects. That probably should not be surprising-most experts concentrate on other dimensions of a CoC's activity, like how well permanent supportive housing adheres to the Housing First model, or what sorts of tools outreach teams use to keep track of unsheltered homeless people and how they prioritize service. These more interesting independent variables have not been studied because no data sets report them for a large numbers of CoCs or considerable periods of time, and because no one has an identifying strategy for using them. Filling this gap is probably crucial for developing useful results about policies for reducing aggregate homelessness.

\section{Prevention}

Homelessness prevention research is particularly interesting because it brings together both aggregate and individual analysis, and shows the strengths and weaknesses of each. New York City began the Homebase prevention program for families in November 2004 in six of its 59 community districts, expanded it to 31 more community districts in July 2007, and the final 22 in January 2008 . This variation, while not completely random, allowed Goodman et al. $(2014,2016)$ to compare entries and exits in "treated" community districts (with Homebase operating) and "control" community districts. They found that Homebase significantly reduced entries but did not significantly affect exits. In addition, in 2010-2011, Abt Associates conducted an RCT where some individual applicants received Homebase services and some did not. Rolston et al. (2013) reported that families who received Homebase services 
were significantly less likely to enter shelters than control group families, and those who did enter spent less time (although the sample of those who did enter is quite small). The two studies ask very different questions, but the answers are consistent enough that careless readers think they say the same thing.

a. Why individual-level studies should not be used to evaluate the impact of prevention programs

There are several obvious reasons why prevention programs might have general equilibrium effects. By keeping certain families housed, they might tighten housing markets and keep other families from becoming housed or continuing to be housed ("musical chairs"). By delaying evictions or allowing families to stay doubled up, they might increase costs to landlords, and discourage landlords from renting to families who might have to be evicted or end up anchoring a doubled up arrangement. By making a more capacious safety net, prevention programs may encourage families to take more risks, and so increase the number of families at risk of homelessness and needing prevention services (whether the number of families actually entering homelessness goes up or down).

On the other hand, general equilibrium effects might also enhance the results of prevention programs. If none of one's friends or none of one's children's friends become homeless and leave the neighborhood, then one may have both greater desire to stay, and greater means, since friends can often provide information and help. So if one family avoids homelessness, other families may be less likely to become homeless. Often prevention programs give families information about how to access help from other agencies; those families can pass that information on to their neighbors, friends, and relatives. And if otherwise unobjectionable tenants can find ways of prolonging their tenancies, landlords will do better and may be more willing to rent to prospective tenants with similar characteristics in the future. 
Thus following only treated and control participants in a prevention program could either seriously over-estimate or seriously under-estimate its impact. We don't know until an aggregate study is done.

But even if prevention programs have no general equilibrium effects-if nothing in the first two paragraphs of this sub-section happens-RCTs have difficulty in generalizing. The problem is that standard RCTs can estimate only one number that can be used for predicting what future homelessness prevention programs will do-the ratio of entries averted to participants served-and that number has little external validity.

The reason is that one of the most important ingredients in a prevention program are the characteristics - particularly the unobservable ones-of the participants served, and those are likely to differ in different prevention programs. No program can avert any shelter entries unless some of the people who show up at its door and ask for services would have entered shelters, and the number of entries averted is limited above by the number of people who showed up at its door and would have entered shelters. Given any recruitment strategy, this number will vary from place to place and from time to time: it will be higher in a poor place in a time of high rents and high unemployment than in the opposite. The number will also differ by recruiting strategy and program accessibility: subway advertisements will draw a different group of people than reliance on word-of-mouth. There is no reason to suspect that if program A serves 100 participants and program B serves 200 participants, exactly the same way once they arrive, program B will avert twice as many homeless entries.

Thus Goodman et al. (2016) estimates of entries averted that were carefully labeled as averages (arithmetic of geometric) of what happened in the period studied, per community-district-month, or per census-tract-month. They also showed that those averages were not constant over time or place. Although they had information about the number of people served by community-district-month or 
census-tract-month, they did not use it, but showed afterward that the ratio of estimated entries averted to people served varied widely (and so did the ratio of actual entries to people served). They had little basis for forecasting what would happen if Homebase expanded or contracted, or if it operated somewhere else, and they did not make any forecasts.

By contrast, in the RCT Rolston et al. produced an estimate of the number of entries averted per 100 people served-about 6.5 [ $95 \%$ c.i. $=14.0,-1.2$ ]. This was pretty close to the estimate of the ratio of total entries averted to total families served in the period Goodman et al. studies: 1200 [95\% c.i. $=168,2375]$ or 1800 [95\% c.i. $=208,3367]$ entries averted when 10,945 Homebase cases were opened. The confidence intervals overlap. Thus we can say that the time that Rolston et al studied (the end of the Great Recession) was pretty close to the average time that Goodman et al studied, unless general equilibrium effects within community districts are large. Neither paper produced a universal constant.

\section{b. What the studies tell us about prevention}

Both papers are probably more useful for some of the ancillary numbers they produced, rather than the headline numbers. Rolston et al. found that 14.5 percent of the control group entered shelters within 27 months, and 8.0 percent of the treatment group. Most families whom Homebase served would not have become homeless in the absence of Homebase services. Another interesting implication is that roughly 45 percent $[95 \%$ c.i. $=.06, .83]$ of the entries that could have been averted were averted; think of this as the efficacy rate. ${ }^{13}$ It is conceivable that the efficacy rate might have more external validity than the ratio of entries averted to families served, since the latter is the product of the efficacy

\footnotetext{
${ }^{13}$ I use the Taylor series approximation for the expected value of the ratio of two random variables (Seltman, n.d.). I used a naïve approximation of the variances of the two variables, as if they were calculated without regressions. As with the mean, I use the Taylor series approximation to the variance of a ratio, and the naïve approximation to the variances of the two variables; then I calculate the 95 percent confidence interval as plus or minus 1.96 times the standard error. Since the ratio of two normal variables has a Cauchy distribution, and the Cauchy distribution has no variance, this approximation to the $95 \%$ confidence interval is probably too narrow.
} 
rate and the proportion of families who would be homeless among the families who seek services, which I'll call the potential aversion rate.

Rolston et al. also compare the treatment and control groups for 27 months in three other domains where administrative data are available: income maintenance, employment, and involvement with the child protective system. Although the treatment group experienced less homelessness than the control group, there were not significant differences in these other domains. The lack of significant difference may be due to the small sample size or the barely significant difference in homeless experience. But it is not surprising, considering the results on Housing First and the Family Options Study.

The most interesting and possibly useful part of Goodman et al. is a series of comparisons of the extent of entries averted by Homebase in different times and places. Because there is no identification strategy for these comparisons, they cannot show causality but some of the differences are intriguing and would probably repay future study.

When Homebase first started, families who did not live in the targeted community districts sometimes showed up and asked for services, although they were ineligible, and sometimes even though they were ineligible they were served (about 600 cases); Goodman et al. called these "unofficial community districts." Even when the program was operating, not all community districts had Homebase offices in them; families from some community districts had to go to a neighboring community district or even further to get services. Goodman et al. found that the harder it was for families to get to a Homebase office, with those in unofficial community districts having the hardest time, the greater the ratio of entries averted to families served. If efficacy rates do not differ by type of community district, then it appears that the harder it was for families to get access to Homebase, the greater the likelihood that those who do make their way to Homebase would have been homeless in the absence of 
Homebase. Perhaps the ideal experiment would be to locate Homebase offices randomly, perturb their locations randomly, and estimate changes in shelter entries as a function of changes in distance to the nearest Homebase office.

This pattern thus suggests that families know something about whether they are likely to become homeless soon. This proposition has never been investigated in New York, but O'Flaherty, Scutella and Tseng (2018a) found that it held in Australia: people at risk of homelessness in the Journeys Home sample had considerable useful information about whether they were likely to become homeless in the near future. Individual-level studies can complement aggregate-level studies.

Why is private information likely to matter? Homelessness is a condition, like being a 23-yearold or having the flu or attending college, not a (relatively) permanent status like being male or Asian or the graduate of a vocational school. For someone who is not homeless to become homeless requires some event, some change of condition (because if a person's permanent status were sufficient to produce homelessness today, it would have produced homelessness yesterday too). Intake questionnaires that concentrate on permanent statuses cannot reveal these events (although they can reveal who is more likely to have such events), but people themselves know when such events occur, although imperfectly. That is why when people travel long distances by public transportation with children in tow to visit a Homebase office, that is a signal that they are likely to face imminent homelessness. The important program design issues are how best to encourage and use these signals.

Fires are a useful analogy. It is easy to compute which buildings are more likely to have structural fires than others, and that information is helpful in deciding how big a fire department to employ and where to place firehouses. But fire departments don't station apparatus next to buildings just because they are wooden, dry, and old. It takes some event to start a fire. That event is not observed by the fire department or recorded in the archives of the building department. Instead, the 
inhabitants of a building (or the building next door) observe a fire, and they call it in to the fire department, which then responds. Calling the fire department is not costless, because penalties for false alarms can be severe. The fire department relies on private information, and on the incentives of citizens to report that information reasonably truthfully. Good homelessness prevention systems will have to do the same.

Finally, it is important to note that no one has yet attempted a serious cost-benefit analysis of homelessness prevention programs. (The attempts heretofore to attach monetary numbers to some aspects of the programs have been parodies of cost-benefit analysis because they calculate only whether relatively affluent people make money from a program designed to help poor people, like similar exercises with Housing First.) Since most people who receive prevention services would not have become homeless absent such services, the major question is what benefits (if any) they receive. Rolston et al. found no benefits, but they looked in only a few places. Being able to continue in a residence without being forced to move, even to other conventional housing, for instance, may be valuable for families with children. The benefits of not becoming homeless have also not been studied extensively, as we noted in section 2, although Johnson and Scutella (2018) have taken a first step with Journeys Home data, and their results suggest that preventing spells of homelessness for men may have greater benefits than shortening them.

\section{Mysteries}

In this section, I look at four areas where large changes in aggregate homelessness have occurred in the last decade, two of them with large increases, and two with large decreases: New York, Los Angeles, veterans, and unsheltered families. I also look at the racial composition of the homeless 
population. I am not aware of a good explanation for any of the changes, or for the composition. These are embarrassments for any claim that we understand homelessness.

\section{a. New York}

As we saw in section 3, sheltered homelessness for both individuals and families rose in New York $^{14}$ after the Great Recession. Homeless population per 10,000 rose from 65.1 in 2010 to 86.1 in 2016, according to AHAR figures. Unemployment fell from 10.5 percent in 2010 to 5.6 percent in 2017, and median gross rent rose from $\$ 1071$ in 2010 to $\$ 1294$ in $2016 .{ }^{15}$ Permanent supportive housing beds increased by 3400 .

Using Corinth's (2017) preferred equation again (table 8, equation IV-2) we obtain an expected increase in New York homeless population of 0.4 per 10,000 between 2010 and 2016. In fact, homeless population per 10,000 increased by 21.1 .

Thus labor and housing market changes and permanent supportive housing do not explain very much about the rise since 2010 in New York homelessness. Rents rose, but not nearly enough to explain the rise in homelessness, especially when the fall in unemployment is also considered. (Cragg and O'Flaherty (1999) and O'Flaherty and Wu $(2006,2008)$ are all papers that include measures of rent and unemployment in regressions explaining the components of change in New York shelter population in earlier periods; rent changes are sometimes insignificant and almost always less powerful than unemployment changes.) Is gross median rent the wrong proxy for housing market tightness?

The Census Bureau takes a special survey in New York every three years called the Housing and Vacancy Survey, and comparing 2011 and 2017 gives us a way of looking at a number of other measures.

\footnotetext{
${ }^{14}$ To recall, "New York" is shorthand for New York City.

${ }^{15}$ I use nominal rents for this calculation, even though I used real in section 3, to make the most favorable case for the proposition that housing and labor market conditions drove the rise in homelessness.
} 
Table 1: Changes in New York City Housing Market Indicators, 2011-2017

$\begin{array}{lll} & \underline{2011} & \underline{2017} \text { (prelim.) } \\ \text { Median gross rent/income ratio } & 33.8 \% & 33.7 \% \\ \text { \% with gross rent }>.5 \text { income } & 32.7 \% & 32.4 \% \\ \text { \% renter households crowded } & 11.5 \% & 11.5 \% \\ \text { Vacancy rate } & 3.12 \% & 3.63 \% \\ \text { Vacant units } & & \\ \text { Vacant and rent }<\$ 1000 * & 67,818 & 79,000 \\ \text { *2017\$, } & 12,600 & 7,900 \\ \text { Sources: Gamer (2018) and Lee (2013). } & & \\ \end{array}$

Table 1 does not indicate any great tightening of the New York housing market between 2011 and 2017. Rents rose, but incomes rose too, and so rent burdens were essentially unchanged. The vacancy rate rose a little, and so did the number of vacancies. The only noticeable tightening is a fall in the number of units available for rent at less than $\$ 1000$ a month (2017 dollars); however, this difference, like most of the rest, does not appear to be statistically significant. Perhaps some other measures would point to greater tightening, maybe in markets more concentrated on poor people, but such measures have not been published yet.

An alternative way to think about whether labor and housing markets explain the rise in homelessness in New York City is to look at nearby CoCs, which faced market shifts similar to the ones New York City faced. Therefore I look at the two New York State CoCs that adjoin New York City, Nassau-Suffolk and Westchester, and six New Jersey CoCs that either adjoin New York City (Bergen, 
Hudson, Union, and Middlesex) or are close nearby and have large cities (Essex and Passaic). Separating the CoCs by state is important because some policies are likely to vary by state. Table 2 shows change in homeless population by major categories.

Table 2: Percent Change in Homeless Population, New York City and Nearby Continua-of-Care

\section{0-2017}

\begin{tabular}{|c|c|c|c|}
\hline & New York City & New Jersey CoCs & New York State CoCs \\
\hline Total & $+43.8 \%$ & $-37.7 \%$ & $+29.0 \%$ \\
\hline Sheltered individuals & +61.1 & -22.6 & +42.2 \\
\hline Unsheltered individuals & +26.5 & +38.3 & +0.9 \\
\hline Sheltered families & +36.7 & -56.4 & +24.4 \\
\hline Unsheltered families & NA & -93.3 & NA \\
\hline
\end{tabular}

Source: HUD, 2007-2017 PIT Counts by CoC.

The New York City rise in homelessness in every category (except unsheltered individuals where the numbers are small and the counting challenges may have been great in the small New Jersey CoCs) is greater than the change in nearby CoCs. Homelessness in New Jersey in fact fell in five out of six CoCs. That homelessness rose in New York State suggests policy differences between the states. I will show later that migration to New York City from these CoCs is not likely to be an explanation for either the City's rise in homelessness or these CoCs" fall.

The comparison here is not definitive, of course, but together with the evidence of only modest tightening of the housing market, it makes the contention that a red-hot housing market doomed New York City to a 43.8 percent increase in homeless population less than completely credible. So we must 
look elsewhere for a story, and we will start with families for children, because a large part of their rise in number is easy to explain.

\section{Families with Children}

For families with children (which includes pregnant women) a great deal of the story is that for over three years New York stopped subsidizing apartments for families who moved out of shelters. During the Great Recession, New York was placing about 700 families a month into subsidized apartments under the Advantage program, which had a time-limited subsidy, among many other rules. In August 2010, the city moved to Advantage 2.0, which changed many rules and lowered the rate of placement to about 300 a month. Finally, in April 2011 all placements ended as a result of either a conflict or an agreement between city and state. Mayor de Blasio took office in January 2014, and placements began again, at a somewhat diminished rate, in September 2014.

Between April 2011 and September 2014, the number of sheltered families rose from about 8168 to 11,613-about 84 more families on net a month (NYC Department of Homeless Services 2018). Shelter population probably could have remained stable or decreased if placements remained about 400-500 a month. From September 2014 to November 2016, shelter population rose to a peak of 13,164-an average of 60 a month more families. Since November 2016, shelter population has declined modestly, about 40-50 a month.

Another way to look at the effect of reduced placements is to consider the length of shelter stays. The average (ongoing) published shelter stay was 258 days in fiscal year 2011, and 430 days in fiscal year 2015, an increase of 66 percent. (City fiscal years end in June.) (New York City Mayor's Management Report FY 2015). Shelter population rose only 43 percent, and so the reduction in exit rate was partially offset by a reduction in entries. Between fiscal year 2015 and fiscal year 2017 the average shelter spell fell 3.4 percent, partly because placements started again, but the average shelter 
population rose by 8 percent (New York City Mayor's Management Report Fiscal Year 2017). So an increased rate of entries has offset the faster rate of exits in the de Blasio years. Entries rose from about 1000 a month in the fiscal year 2013 and 2014 at the end of the Bloomberg administration to about 1100 a month in fiscal year 2016 and back to about 1050 a month in fiscal year 2017.

Why did entries rise? I don't know. Rising rents are a possibility, and my argument earlier was only that labor and housing market conditions did not explain all of the rise in shelter population, not that they explained none of it. Part of the reason might be greater migration of homeless families to New York, but neighboring areas did not drastically reduce their generosity toward families, as far as I know. However, part of the reason is pretty likely to be a "looser front door."

The looser front door refers to the process by which families are admitted to the shelter system. Since the mid-1990s, families have been vetted before they were admitted to the shelter system; families cannot simply claim to be homeless. Most families who apply are rejected. The process of checking eligibility is arduous, and involves many rules but also considerable discretion for staff; essentially families must prove they have no reasonable alternative to shelter. Subtle changes in what the staff thinks is expected of them, and not so subtle changes in written guidelines, could result in small changes in the rate at which families are accepted, and because so many families apply each month, small changes in acceptance rates over time can make a large difference in shelter population.

I have no evidence of changes in attitudes of intake staff, but important changes in the guidelines for eligibility took place during the de Blasio years. In Septermber 2015, New York State, at the request of the City, issued revised guidelines-called "15-ADM-06"-- on how to determine whether families had "available housing resources": families with such resources are not permitted to enter shelters (Jorgenson 2017; New York State Office of Temporary and Disability Assistance 2015). These revisions made it easier to qualify for shelters entry. Between September 2014, when placement 
activity resumed, and September 2015, shelter population rose by only 25 a month on average. For the next 14 months, the proportion of applicants for shelter who were determined eligible rose from around 40 percent to around 50 percent (Jorgenson 2017), and shelter population rose by around 90 families a month. In November 2016, the State, acting once again at the behest of the City, revised the guidelines again in 16-ADM-11 (New York State Office of Temporary and Disability Assistance 2016), and tightened them considerably (Jorgenson 2017). Eligibility rates returned to their pre-2015 levels, and November 2016 became the peak month for shelter population; the decline started then.

What sort of changes to the guidelines were made by 16-ADM-11? The key change was the addition of the following sentence, once in the definitions and again in the procedures that agencies have to follow (p. 4, section V.A. definition of "available housing resources," and p. 10, section D.2): “Applicants for temporary housing assistance claiming they do not have control or permission [to stay at an apartment somewhere] must support those claims with clear, convincing, and credible evidence." 16-ADM-11 also made it harder for an applicant to claim that she could not stay with a friend or relative because that friend or relative had not secured landlord's permission (p. 4, section V. A., definition of "available housing resource"): "Refusal by a primary tenant or leaseholder to seek permission where clear, convincing, and credible evidence exists that such permission would be granted does not make the housing resource unavailable."

Did these administrative directives cause the acceleration in shelter population growth after September 2015 and its deceleration after November 2016? I don't know. The claim is plausible because the first-order, purely mechanical effect of a 10 percent increase in the eligibility rate is large, an increase in shelter entries of around 200 a month. But many other things were going on at this time, and serious econometric work is needed to figure out what really drove shelter population after the placement hiatus. 
What about prevention services? Why didn't prevention cut off the rise in entries? It was not for lack of trying. De Blasio expanded prevention efforts greatly, and added many new twists-providing lawyers, for instance, for many families facing eviction and stepping up emergency assistance payments in the income maintenance system. During the period that Goodman et al. studied, 2004-2008, a fully operating community-district-month served on average 10.3 families. When the Abt RCT was conducted in 2010, the rate of service was similar. In fiscal year 2016, the average community-district-month saw over 35 families (De Blasio, 2017, p. 28). This increase in Homebase was accompanied by many other initiatives.

As I have noted, research so far tells us little about what happens when a program like Homebase is scaled up, although considerable indirect evidence suggests that marginal returns are decreasing, and perhaps sharply so. To infer something about homeless prevention services on the scale of 2016 and 2017 from the studies of Homebase in 2010 and before is like inferring from one's success in using a brush to lull a house cat to sleep that a very large brush is all one needs to lull a hungry lion to sleep.

Still, the fall in exits for reasons other than placement is the bigger puzzle and probably the main reason why the family census rose so high after placements began again and has stayed so high (and because migration from outside the city affects entries but not exits, the importance of exits indicates that changes in migration are unlikely to be a major cause of the New York shelter census increase). Over three years of placement activity at a scale approaching that of the early part of the century have moved the average spell down only from 427 days in fiscal year 2014 and 430 days in fiscal year 2015 to 414 days in fiscal year 2017. Remember that the average spell was 243 days in fiscal year 2010 and 258 in fiscal year 2011. Again, I don't know why these large efforts have yielded so little. Part of the reason is arithmetic: the shelter census was more than 40 percent larger in the de Blasio years than it was in the 
Great Recession, and so even if placements had been occurring as fast as they were in the Great Recession the impact on the spell distribution would have been less.

Another reason may be more subtle: relative to placements in the Great Recession, de Blasio placements were both less numerous and more attractive. Great Recession subsidies (the Advantage program) were limited to two years, and advocates, whom de Blasio embraced, had attacked them on those grounds. When subsidies returned in late 2014, they allowed extensions of up to four or five years. So families would have to wait longer for subsidies, but their reward for waiting was greater. Rare and expensive subsidies can easily induce longer shelter stays than cheap and plentiful ones (clearly this remains an area for serious empirical research), and the de Blasio approach has leaned toward rare and expensive.

Improving shelter quality may also have made families more reluctant to leave on their own. De Blasio criticized shelter quality in his campaign, and appointed as his chief administrator for homelessness a lawyer who had been litigating for over two decades to improve shelter quality. Expenditure per family-day rose from $\$ 103$ in fiscal year 2014 to $\$ 171$ in fiscal year 2017 (MMR, 2017). Part of the rise in expenditure is probably due to using more expensive facilities like hotels as the census expanded, but probably not a large piece, as most of the expansion was complete after fiscal year 2014. Whether the better quality shelter was closer to optimal is a question that needs study. (Because average shelter spells increased, relative to 2010 , and cost per day also increased, the expected cost to the city of a shelter entry was about $\$ 75,000$ by fiscal year 2018 , and so the financial benefits of prevention programs were also greater, per entry averted; even with diminishing returns in averted shelter entries, the expansion of prevention efforts may have made sense from the city financial perspective.) 
Thus overall we have a reasonable picture, although one with a few holes, of why sheltered homelessness among families with children rose after 2010. For the other two categories New York uses for sheltered population, single adults and adult families, the story is less clear.

\section{$\underline{\text { Single adults and adult families }}$}

New York divides the AHAR category of "individuals" in two: single adults and "adult families" any group of adults unaccompanied by children. Historically, single adults (single men, more precisely) were the only group labeled "homeless" in New York, and the Callahan v. Carey decision in 1979 was about single men, not women or families. About 1500 single men were homeless in 1979, but the population (of both genders) rose swiftly after Callahan v. Carey, peaking at around 10,000 in the mid1980s (O'Flaherty 1996), and declining to around 5000 at the turn of the century. It rose again to around 6000 at the start of the Great Recession (O'Flaherty and Wu 2008). The population swelled modestly during the Great Recession and stood at 8629 in April 2011, the benchmark month for families (NYC Department of Homeless Services 2018). In the recovery from the recession, it rose to 10,759 in September 2014-about 55 more people a month. And it has continued to rise even faster since then, standing at 15,356 in April 2018-an increase of 100 a month since September 2014.

Adult families were originally considered part of the family population, and were not split off from families with children until this century. At the start of the Great Recession, 1,139 adult families were sheltered. The number rose to 1,308 in April 2011 and 2,103 in September 2014. By April 2018, it was 2,421 . The rate of increase was 25 families a month in the late Bloomberg administration, and 7 families a month in the de Blasio administration.

For single adults, the rise in population does not seem to be due to more entries-and so the rise is unlikely to be due to greater migration from outside the City. The number of entries fell from 20,615 in fiscal year 2011 to 12,306 in fiscal year 2012, and stayed around that level for the next five 
fiscal years. The average length of stay, however rose monotonically from 250 days in fiscal year 2011 to 383 days in fiscal year 2017. A shelter spell for single adults is defined not to be interrupted by short periods of living outside the shelter, and so because the percentage increase in point-in-time count is greater than the percentage increase in average spell length, it appears that single adults had fewer and shorter gaps in their shelter spells.

For adult families, greater average length of stay also appears to be a major factor in their increasing shelter population. It rose from 349 days in fiscal year 2011 to 563 days in fiscal year 2016 before falling back slightly to 550 days in fiscal year 2017. But entries also increased, from 1,096 in fiscal year 2011 to 1,583 in fiscal year 2017.

Thus the big unanswered question for research is explaining why single adults and adult families are staying in shelters so much longer. O'Flaherty and $\mathrm{Wu}(2008)$ found that housing and labor market conditions had modest but often insignificant effects on single adult shelter exits during the late $20^{\text {th }}$ and early $21^{\text {st }}$ centuries, and so the conflicting effects of falling unemployment and rising rents are unlikely to explain this phenomenon. But no serious research has been done on this question in over a decade.

What are the other possibilities? Rising shelter quality may have contributed. Expenditure per day for private facilities rose from $\$ 73$ in fiscal year 2011 to $\$ 99$ in fiscal year 2017; for adult families, the rise was from $\$ 97$ in fiscal year 2013 to $\$ 138$ in fiscal year 2017 . But the elasticity of shelter population with respect to shelter quality (the elasticity of the need curve) would have to be very big for quality improvement to explain the whole rise (especially since part of the expenditure increase in this case also is caused by the shelter population expanding into ever more expensive but not necessarily more attractive facilities).

The rise in average length of stay after September 2014 is also remarkable because the city reinstituted subsidies then for adult families and single adults to leave shelters. Before this, subsidies 
were mainly confined to families with children, although enough subsidies for single adults were available for O'Flaherty and $\mathrm{Wu}$ (2008) to find that they seemed to work pretty well, with 100 placements reducing shelter population by about 50 .

But a quick look at crude data suggests that post-2014 subsidies may not be as effective as earlier ones. In fiscal year $2013,8,526$ single adults exited to housing, and none were subsidized; this was normal for the late Bloomberg period. By fiscal year 2017, 3,770 adult exits were subsidized, but unsubsidized exits fell by 4,162 (even though the base of shelter residents who could exit was considerably bigger), and so the number of exits to permanent housing actually fell. Of course, other things happened too between these two years. A serious study should be undertaken. Perhaps my speculations for families with children about the problems of dangling a small number of large subsidies for those who remain in shelters the longest applies to single adults and adult families.

\section{Big questions}

New York now spends about $\$ 1.8$ billion a year on homelessness, up from about $\$ 1.0$ in fiscal year 2014 (MMR 2017). For the entire US, the appropriation for HUD's basic homeless assistance grants is $\$ 2.4$ billion (this doesn't count veterans' programs).

Is this $\$ 1.8$ billion a year worth it? New York has a very low and stable unsheltered homeless rate, and the incidence of sheltered homelessness is also low. It is only because of the extremely long shelter spells that the point prevalence of homelessness is high. (In 2016, the average shelter stay for individuals nationally was 80 days, compared with 355 days in New York. For families with children, the national average including New York was 118 days, against New York's 431 days (AHAR 2016, part 2, pages 2-15 and 3-17)). If the harm from homelessness is concentrated on entry, then New York is really close to the rest of the country, and probably better, if unsheltered homelessness is considered too. 
What difference in people's lives do these long and expensive shelter stays make? This is an important research question. For families, it would be very useful to compare families who were denied shelter entry with those who were not, probably using random differences in intake strictness with methods like those popularized by Doyle (2008), or using the guideline changes of September 2015 and November 2016. Many children whose families applied for shelter in the 1990s are grown up now, and so even long-term developmental effects might be able to be discerned. This research should also contribute to a sensible discussion of whether the front door is too loose or too tight. Loosening the front door almost certainly increases shelter population, but how large are the benefits that families who are admitted gain?

But the Family Options Study can also shed light on the value of long shelter stays. The negative results in that study about transitional housing, the option that most resembles New York's family shelter system, suggests that long and expensive shelter stays do little to improve families' lives. Housing subsidies dominate transitional housing on practically every measure.

Of course, the prospect of immediate subsidies like housing choice vouchers might bring many more households into the homeless system. But the $\$ 1.8$ billion a year that New York now spends could be cashed out into around 160,000 Housing Choice Vouchers, compared with a point-in-time shelter count of around 30,000 households (April 2018), half of them with only a single member. Nationally about 14 percent of Housing Choice Vouchers turn over each year (McClure 2018, p. 19), and so with 160,000 vouchers, over 22,000 would open up annually. About 33,000 households entered the shelter system in fiscal year 2017, and so some emergencies might not be able to be handled, but many of the 33,000 households are re-entries, especially among single adults, that might be avoided with large numbers of housing subsidies around, and the many single adults receiving vouchers might also turn over faster than the current national population of voucher-holders. On the other hand, the prospect of immediate "permanent" housing subsidies might incentivize more eligible households to apply, or to 
migrate to New York, and these effects might more than offset the reduced re-entries and increased turnover. Possibly reducing the generosity of the vouchers could reduce incentives, and the subsidies might also be redesigned to encourage more shared housing.

But I am not advocating cashing out the New York homeless system; I am using this as a thought experiment. The point I want to make is that 160,000 Housing Choice Vouchers or a different probably larger number of alternatively designed housing subsidies would do almost everything the shelter system does now almost as well, and it would do some important things much better. The real issue is how to implement right-to-shelter.

If some city were to adopt a right-to-decent-shelter policy de novo, most of the discussion would probably be around the definition of "decent shelter" and about some system of housing subsidies (possibly resembling Housing Choice Vouchers) to implement it for large numbers of people. The quality standard and the cost would probably be discussed simultaneously. After a plan was developed for the large number of households who would need some help meeting that standard without greatly sacrificing other consumption, attention would turn to how to deal with emergencies and people with serious mental illness and substance abuse problems within this framework. The plan that would be developed de novo for New York in this process would almost certainly not include housing 12,000 families at a cost of over $\$ 5,000$ a month each.

That sensible approach has not been what occurred in New York. Right-to-shelter was introduced with the Callahan v. Carey decision, which concentrated on keeping several individuals, at least one of whom was seriously alcoholic, from freezing to death on the streets as winter approached. So the original discussions were about emergencies and pathologies, not about standards and the people without serious pathologies who could use some help meeting the standards. 
Over time, the system has come closer and closer to the sort of universal system that right-toshelter implies - that is probably why it keeps growing over the long haul. Each step of this process, however, has not been taken by acknowledging that a right-to-shelter requires helping ordinary people who have problems paying for houses that meet reasonable standards. Instead, it expanded by incorporating more conditions into emergencies-and-pathologies. So, most tellingly, instead of directly subsidizing housing for eligible families, it rationed subsidies by requiring long shelter stays, because long shelter stays were an ordeal that would demonstrate (at great cost to the city) which families truly could not cope.

Here is an apocryphal analogy. A city is operating a free emergency room for medical emergencies, and then it learns that there is a right-to-healthcare. Instead of starting from scratch with a system for healthcare of all varieties, it maintains an emergency room as the only point of access to healthcare for those who cannot pay for it themselves. Over time, it comes to define all manner of conditions-cancer and obesity, diabetes and asthma-as medical emergencies and to avoid being inundated, it requires that anyone presenting to the emergency room first get treated as an emergency case. So cancer patients have their legs put in casts, diabetes patients start with coronary artery bypass operations, and asthma patients first get shocked with defibrillators. Everyone has to arrive in an ambulance with sirens and flashing lights. The system is very expensive, but it keeps the number of patients being treated manageably low.

The point is not that either emergency rooms or right-to-healthcare is a terrible idea; it says nothing about those propositions. Instead the point is that using an emergency room is a bad way to implement a right-to-healthcare. But it is no sillier than using emergency shelters to create a right-todecent-shelter, which is the path that New York has been following for the last forty years.

\section{b. Los Angeles}


Just as labor and housing market changes explain little of the rise of New York homelessness since the Great Recession, they also explain little or nothing of the rise in homelessness in Los Angeles. Unemployment in Los Angeles in the Great Recession was higher than it was in New York, and so Cornish's table 8, equation IV-2 implies that homelessness in Los Angeles should have been expected to fall from 37 per 10,000 in 2010 to 36 per 10,000 is 2017. Instead, homelessness rose to 47 per 10,000 in 2017.

As with New York, the CoCs closest to Los Angeles, and so part of the same housing and labor markets, do not show a trend like that in Los Angeles. Between 2010 and 2017, the combined homeless population of Long Beach, Pasadena, and Glendale fell by more than half. The decrease was more or less uniform across these CoCs and across categories of homelessness, except that the number of unsheltered individuals fell by only 31 percent. These three communities are all part of the legal and political jurisdiction of Los Angeles County, but operate their own homelessness programs.

Thus it is unlikely that housing and labor markets fully explain the rise in the Los Angeles CoC. Los Angeles homelessness has been studied less than New York homelessness, and unsheltered homelessness is harder to learn about than sheltered. So much less is known about Los Angeles than New York City.

Indeed, even basic facts like the size of the increase (or even its existence) are not known with greater certainty because the quality of the count of unsheltered homeless people is low. For instance, the original data that Los Angeles submitted to HUD for the 2007 and 2008 AHARs showed over 65,000 homeless people then (compared with 55,000 in 2017), but HUD eventually rejected these numbers and published different ones now for those years (National Law Center on Homelessness and Poverty 2017). The issue was about the unsheltered count: Los Angeles was using a sample of homeless people spotted 
in backyards as part of its count. Starting in 2009, Los Angeles dropped the practice, but year-to-year comparability in survey results remains difficult (Flaming and Burns 2017).

Los Angeles relies on around 8000 volunteers now to conduct the survey. Training for them is a 13-minute video (available at https://www.theycountwillyou.org/training ), a substantial portion of which is devoted to instructing volunteers to be safe. The survey is completely visual: the volunteers do not speak to anyone and have to decide for themselves which people they see are homeless, and which vehicles and street structures have homeless people in them. The video tells them a few clichéd stereotypes, and then asks them to use their judgment. (By contrast, the New York survey provides volunteers with an oral script and lets interviewees describe their circumstances.) The volunteers are given areas to cover and maps, but not told what route to follow (again, unlike New York). Many of the areas the volunteers are supposed to traverse are huge; the example in the video included 16 miles of streets (32 miles for both sides, the way New York would measure). Many areas are "covered" by car, not by foot (New York relies on a foot survey, with only a few exceptions like certain parks, where park employees count). No special provision is made for mass transit (New York has a subway division with special procedures). There are no quality controls, like the decoys that New York and Toronto use (Flaming and Burns 2017).

Along with the visual survey, Los Angeles also uses a questionnaire to take a demographic survey. But the survey is administered to what is apparently a convenience sample of unsheltered homeless people, not a random sample (Flaming and Burns 2017), although whether it is a convenience sample is subject to some disagreement. The results are used not only for information about demographic characteristics and length of homelessness, but also to complete the count of unsheltered homelessness. The visual survey results tell how many vehicles and street structures the volunteers found (and somehow thought that homeless people were using), and the demographic survey provides 
results about the average number of people that might be expected to be in those objects (presumably when the volunteers looked at them). People presumed to be in vehicles and street structures are a major part of the unsheltered count-the majority in recent years-and so these parameters derived from a convenience sample carry great weight. They are also unstable from year to year (Smith and Zhang 2016).

But while skepticism about what exactly has been happening is in order, perception among Los Angeles citizens and officials is that homelessness has been rising, and it is more likely than not that the perception Is valid. Unfortunately, aside from obeisance to the housing market, no clear hypotheses about the reasons for the increase have been put forward, much less tested. I have found no serious discussion about aggregate homelessness.

Migration is often discussed as a possible cause. Unlike New York, where the data showed that migration was not a plausible hypothesis because the change in shelter population was mainly driven by longer stays, not faster entries, Los Angeles does not have a good data on changes in spells and changes in entries, and so the migration hypothesis cannot be dismissed so easily. Pointing out the Los Angeles is warm is not a sufficient argument for migration; many other cities that did not have large increases in homelessness are just as warm (Houston, for instance). A plausible argument for the migration hypothesis has to show that the relative advantage for unsheltered homeless people of Los Angeles over other warm cities increased for some reason in this period. This might be the case, but I have not yet seen such an argument.

Since the rise is primarily among unsheltered individuals, one obvious candidate explanation for the increase (and for the migration hypothesis) is change in policing (for the migration hypothesis, this would have to be a larger shift to leniency in Los Angeles than in other warm cities). The picture that Stuart (2016) paints of police treatment of unsheltered homeless people at the beginning of this period 
is not an inviting one. But policy discussions about treatment of unsheltered homelessness have ricocheted erratically between extremes, from installing portable toilets and dedicated parking lots, to confiscating possessions, and it is not clear how much of any policy was actually implemented. These discussions seem to bear little correlation with future changes in homelessness. Of course, since data on purported unsheltered homelessness is available for over a decade on a rich geographic basis, and several announced policy changes are probably exogenous (removal of portable toilets after photographs of prostitutes using them appear in the media, for instance), useful research can probably be done on how policy affects unsheltered homelessness.

Several court decisions, too, may have affected unsheltered homeless population. In the Jones decision (Edward Jones et al., v. City of Los Angeles et al., U.S. Court of Appeals, Ninth Circuit, No 0455324) in April 2006, the Ninth Circuit effectively set aside the city's Municipal Code section 41.18(d), which stated, "No person shall sit, lie, or sleep in or upon any street, sidewalk or other public way" except while watching a parade. They did not strike the section down, but required that so long as there is a greater number of homeless individuals than the number of available shelter beds, the city may not act to enforce section 41.18(d) at all times and places against homeless individuals involuntarily sitting, lying, or sleeping in public.

In Tony Lavin et al., v. City of Los Angeles (Ninth Circuit, No. 11-56253) decided on September 5, 2012, the Ninth Circuit upheld a district court injunction issued in April 2011 that barred the City of Los Angeles from "seizing property in Skid Row absent an objectively reasonable belief that it is abandoned, presents an immediate threat to public health or safety, or is evidence of a crime, or is contraband." This decision set off many attempts by the Los Angeles City Council to craft an acceptable ordinance on homeless people's property, and continuing litigation. 
Finally, in the Desertrain decision in June 2014 (Cheyenne Desertrain et al. v. City of Los Angeles et al., U.S. Court of Appeals, Ninth Circuit, No. 11-56957), the Ninth Circuit struck down section 85.02 of the Los Angeles Municipal Code: "No person shall use a vehicle parked or standing upon any city street, or upon any parking lot owned by the City of Los Angeles ... as living quarters either overnight, day-byday or otherwise." The reason was vagueness.

It is not clear how these decisions affected unsheltered homelessness, partly because enforcement of the contested laws was sporadic before the decisions, and continued in various revised and modified ways afterwards. This is another area where scholarship could likely find something worthwhile (although the Jones decision may have been handed down before consistent data were available).

Because these decisions applied directly to the City of Los Angeles, all of these decisions divided Los Angeles County into three parts where different policies might have applied: the City of Los Angeles, the rest of the Los Angeles $\mathrm{CoC}$, and the three cities with their own CoCs. Table 3 shows how unsheltered homelessness evolved since 2011 (the first consistent data). This table suggests that Lavin (2011-2012, seizing possessions) may have made a difference, since the unsheltered homeless population increased more in the City of Los Angeles than elsewhere in 2011-2013 period when this decision would have had an effect, but that Desertrain (2014, living in a vehicle) did not, looking at the 2013-2015 period.

Table 3: Percent change in Unsheltered Population in Los Angeles County, 2009-2017

\section{Annualized Average Rates of Change}

$\underline{\text { Period Los Angeles City }} \underline{\text { Rest of LAHSA Other CoCs }}$ Legal developments


2013-2015 9

22

$-10$

Desertrain (cars)

2015-2016

2011 data for LAHSA areas does not count hidden homeless. It is from the 2013 report. 2009 data is not corrected.

Sources: For outside the Los Angeles CoC, data are from HUD, 2007-2017 PIT Counts by CoC. For Los Angeles City and the rest of LAHSA data are from LAHSA.

2009: https://www.lahsa.org/documents?id=2002-2018-greater-los-angeles-homeless-count-losangeles-continuum-of-care.pdf

2011:

https://documents.lahsa.org/planning/homelesscount/2013/HC13-Results-LACounty-COC.pdf http://documents.lahsa.org/planning/homelesscount/2013/2013-Homeless-Count-Results---LA-City-\&-CDs---FINAL.pdf 2013:

https://documents.lahsa.org/Planning/homelesscount/2013/2013HomelessPopulationsandSubpopulati onsDataSummaries-CA-600LosAngelesCityandCountyCoC.pdf

2015 and 2016:

https://documents.lahsa.org/Planning/homelesscount/2016/datasummaries/CoC.pdf https://documents.lahsa.org/Planning/homelesscount/2016/datasummaries/La City.pdf

2017: https://www.lahsa.org/news?article=408-revised-2017-homeless-count-results 
Whatever explains the rise in Los Angeles homelessness, the amount of money that Los Angeles spends on homelessness explains why its activities differ from New York's. In fiscal year 2015, the Los Angeles Homeless Services Authority (LAHSA), which administers homeless programs for the CoC, spent about $\$ 63$ million (Davis Farr, 2017). This amount seems to have been its budget for the previous decade or so, except for additional money from HPRP during the Great Recession. Spending rose to \$76 million in fiscal year 2016, as public awareness of a "homeless crisis" grew. By contrast, New York's Department of Homeless Services spent $\$ 941$ million in fiscal year 2015, and $\$ 1.12$ billion in fiscal year 2016-about fifteen times as much, even though New York City's population was less than that of the Los Angeles CoC, and New York's volume of homelessness was only slightly larger (MMR 2017, p. 212). (However, the VA probably spends more money in Los Angeles than in New York because there are more homeless veterans in Los Angeles.) It is highly doubtful that both New York and Los Angeles had optimal budgets at this time.

Since 2017, however, more money has become available. On March 7, 2017, Los Angeles County voters approved Measure $\mathrm{H}$, which enacted a $0.25 \%$ county sales tax for ten years to fund homeless services and prevention. This tax is projected to raise about $\$ 355$ million a year, a portion of which is earmarked for the three cities that are independent CoC (Smith 2018).

Earlier, in November 2016, Los Angeles city voters approved a $\$ 1.2$ billion bond issue to construct 1000 apartment units a year for ten years, with an emphasis on the most medically vulnerable homeless people. This is known as proposition $\mathrm{HHH}$. The first project broke ground thirteen months later (Chiland 2017). The emphasis was on building permanent supportive housing, but as the program developed other kind of non-luxury housing are being included (Community Action Network 2017). 
There seem to be no plans to eliminate or drastically reduce street homelessness in Los Angeles. Shelters for 40,000 currently unsheltered homeless people even at $\$ 50$ a day, which is half of the price of single adult shelters in New York, would total about $\$ 730$ million a year, more than twice as much as Measure $\mathrm{H}$ raises, and shelters would almost certainly serve some people who would not otherwise be homeless on the street. In fact, the budget for the second year sets aside only $\$ 120$ million for shelters and interim housing, and talks about only a few thousand beds (LAWT News Service, 2018).

What about the other components? If Proposition HHH does eventually add 10,000 permanent supportive housing beds in a decade, homelessness could be expected to fall by about a thousand, as we have seen. The second year budget from Measure $\mathrm{H}$ includes $\$ 17$ million for prevention, $\$ 73$ million and \$49 million for rent subsidies.

During the period in which Homebase in New York was studied, it cost about $\$ 30,000$ for each shelter entry averted, and because shelter stays were then averaging about a year in length, averting a shelter stay was loosely equivalent to a reduction of one in the point-in-time count. Los Angeles' incidence of homelessness is almost certainly more than New York's, but its homeless spells are probably shorter. If those two effects just happen to cancel out, prevention in Los Angeles might also require around $\$ 30,000$ to reduce the point-in-time count by one. So $\$ 17$ million for prevention would reduce the point-in-time count about 500-600.

On rent subsidies, the effect is harder to gauge. A year of rent subsidy would probably cost around $\$ 10,000$, but a household would hold the subsidy for several years on average. If the New York ratio of 100 new subsidies to $20-40$ point-in-time count reduction holds, then in the long run, reducing the point-in-time count by one would cost $\$ 40,000-80,000$. So the $\$ 122$ million for rent subsidies would reduce the point-in-time count by about 1,000-4,000, if they were all used. 
In all, the two initiatives do not seem destined to reduce the point-in-time count by more than 5 or 10 percent, if the relationships that appear in current empirical work hold. Of course, since current research does not explain why homelessness rose so much in Los Angeles since the Great Recession, we also don't know what might or will make it go down again.

Many of the measures projected for Los Angeles under proposition $\mathrm{HHH}$ are designed not to reduce street homelessness, but to create a large but well-groomed and well-mannered street population: dedicated parking lots, storage facilities for possessions, portable toilets, and drop-in and hygiene centers. The big research question is how does this new mode of homelessness affect the people who experience it? To what extent is a car a good substitute for an apartment? Is it really possible to create a well-groomed and well-mannered street population? Studies like Journeys Home are needed to resolve this question.

More generally, economists have studied unsheltered homelessness very little. Corinth and Lucas (2018) note that warm weather is not a sufficient reason for high rates of unsheltered homelessness; many cities with warm climates have few people on the streets. Much of the variation in unsheltered homelessness cannot be explained by standard covariates like labor and housing markets; they speculated that enforcement practices may differ. Suppose that enforcement practices are the reason. What happens to people in strict enforcement cities when they suffer the shocks that put their counterparts in lax enforcement cities on the streets? Do they go to shelters, migrate, or double up? And what difference does it make to their lives whether they live in a lax enforcement city or a strict one? A Journeys Home for the US with a large sample could answer these questions. (Probably not Journeys Home itself, though. Australia has many warm cities and they may differ in enforcement, but Journeys Home includes very few spells of unsheltered homelessness.

\section{c. Veterans}


The 46 percent decline in veterans' homelessness that occurred between 2010 and 2017 is often hailed as one of the triumphs of homeless policy. It followed the federal declaration in 2009 that ending veterans' homelessness was a national priority, and big increases in appropriations were made for this purpose. The best available research was applied.

A new program of prevention and rapid rehousing, Supportive Services for Veteran Families (SSVF) was created and grew to appropriations of over $\$ 300$ million a year. The HUD-VASH program, in which Housing Choice Vouchers are distributed with supportive services wrapped around them, grew from about 20,500 vouchers in September 2010 (Pittman 2013) to 72,500 in September 2016 (AHAR 2016 part 2, p. 7-17). The U.S. Department of Labor began the Homeless Veteran Supported Employment Program, which had an appropriation of $\$ 45$ million federal fiscal year 2018 . The existing Grant and Per Diem transitional housing program continued.

But whether this well-planned and well-directed activity had a large effect is unclear. Between 2010 and 2016, the number of veterans between 18 and 65, the ages at which homelessness is most likely, fell by 26.7 percent, according to the American Community Survey one-year estimates (ACS). Projecting that rate of decrease to 2017 implies a $30.4 \%$ fall in the number of veterans in the age range susceptible to homelessness. In section 3 we saw that per capita homelessness fell 18.5 percent overall in this period. Per capita incidence of sheltered homelessness for children fell faster than for adults in this period, and the proportion of US population over 65 rose. So if we restrict attention to people between 18 and 64, and make some heroic estimates because the age distribution of the PIT homeless population is unknown, per capita homelessness for people $18-64$ fell only around 16.0 percent. ${ }^{16}$ Thus if the fall in per capita homelessness among veterans were the same as that among the 18-64

\footnotetext{
${ }^{16}$ This is the percentage decrease from 2010 to 2016, and uses the age distribution for the incidence of sheltered homelessness rather than for PIT homelessness. The age distribution for 2017 has not been published yet, but the PIT count rose slightly between 2016 and 2017.
} 
population at large, the number of homeless veterans would have fallen 41.5 percent (compared with the actual fall of 46 percent $)^{17}$. This great initiative appears to have accomplished little.

In the appendix, I show that this result is robust to considering changes in the age distribution and to considering other sources of information on the size of the general veteran population. Of course, the correlation between the fall in the number of veterans on a national basis and the fall in the number of homeless veterans on a national basis may be just a coincidence, and CoC level studies (for instance, Blinder-Oaxaca decompositions where the two groups are veterans and non-veterans and the dependent variables are changes in number of homeless) are needed to test for anything approaching causality.

Looking at sheltered homeless incidence suggests a more striking result about veterans in a period when special policies for them were supposed to be effective. Between 2010 and 2016 (AHAR data on incidence for 2017 have not been published yet), the per capita incidence of sheltered homelessness for veterans rose by 20 percent while the per capita incidence of sheltered homelessness for the general population 18-64 fell by 13 percent. Veterans did worse than the general population in every age category except 30-49, where per capita fell 20 percent for veterans an d 19 percent for the general population. The divergence was particularly great for the veterans between 62 and 65 , whose per capita incidence appears to have more than tripled, while per capita incidence in the general population for that age group rose only 34 percent.

Of course, most knowledgeable observers today think that prevalence is a more important measure than incidence, but that belief, as I emphasized in section 3 , is supported by little hard

\footnotetext{
${ }^{17}$ An alternative decomposition would give some more prominence the HUD-VASH vouchers. The total decrease in homeless veterans was 34,000 . Population decline accounts for most of that, 22,500. Net changes in housing and labor market conditions account for 1,000 more of the decrease, and the increase in HUD-VASH for 5,200. This leaves a residual unexplained of 5,300. But the general population residual would account for 2,200, leaving the extra efforts of the VA and the rest of the government to be responsible for the remaining decrease of 3,000.
} 
evidence. However, the incidence of sheltered homelessness policy implications differ from those of the incidence of general homelessness: if shelter homelessness incidence rose among 62-64 year old veterans because they came in off the streets, then the policies that caused this were probably successful. But none of the headline pieces of the campaign to end homelessness among veterans had moving older veterans into shelters as a goal, and one major program, SSVF, was explicitly designed to reduce the incidence of homelessness.

The only currently published aggregate-level study of veterans' homelessness, Montgomery et al. (2015) suggests that the one part of the initiative, HUD-VASH vouchers, did not reduce the ratio of unsheltered to sheltered homelessness. Holding many other variables constant, they find that the number of HUD-VASH vouchers in a metropolitan CoC is uncorrelated with the ratio of unsheltered to sheltered homeless population. They do not have an identification strategy and they do not control for temperature or other weather conditions, and so more work can be done on this question.

Are these back-of-the- envelope calculations justified? Was there some mitigating factor that would have increased veterans homelessness absent this initiative? Did more homeless people start to say that they were veterans, rightly or wrongly? Were there some parts of this program that worked and others that did not? I don't know. Except for Montgomery et al. (2015), I can find no studies of the aggregate effects of this initiative. The need for research on this topic is obvious.

\section{d. Unsheltered families}

Between 2010 and 2017, the number of homeless people in unsheltered families with children fall by two-thirds, from 50,600 to 16,900 . We don't know why this happened. There are three possibilities. 
Changes in counting methods-possibly improvements-may have been responsible. In 2010, many unsheltered families were counted in rural areas. Doing a street count for an area of hundreds of square miles, much of it farmland or forest or desert, is a daunting task, and whatever results were achieved will have large standard errors (because the number of volunteers to do the counting will be small). For instance, around 33 CoCs are called "balance-of-state": they are areas that are not densely populated enough to support a major city or county. These CoCs accounted for about a third of the count of people in unsheltered families in 2010, and a slightly higher fraction in 2017.

Another possibility is that child protection services in some states have become more active, and no longer permit children to be unsheltered. New York State, for instance, has long had a policy of removing any child from an unsheltered family, and any child whom counters can see, child protective services can see and remove. More states may have adopted New York's practices.

The third possibility is that the decline in the number of people in unsheltered families may be a true success story, for some other reason than the removal of children. It would be good to find out.

\section{e. Race}

The homeless population, especially the sheltered homeless population, is disproportionately African American. "Although Black people comprise 13 percent of the general population in the United States and 26 percent of those living in poverty, they account for more than 40 percent of the homeless population ...." (Olivet et al. 2018, p. 6).

Los Angeles is an extreme example. Although only 9.0 percent of the population of the $\mathrm{CoC}$ is Black, around half of homeless people are Black. Understanding homelessness in Los Angeles is impossible without understanding this disproportion. Among Blacks in Los Angeles, the rate of 
homelessness is around 300 per 10,000. By contrast, the rate among Blacks in New York is around 160 per $10,000^{18}$ - extremely high but not close to the apparent rate in Los Angeles.

On the other hand, homelessness tends to be uncommon in the states with the highest proportion of African Americans. In Mississippi, for instance, only 4.9 people per 10,000 were homeless in 2017 (compared with the national rate of 16.8 per 10,000). The rate was 7.8 for Alabama and South Carolina, 8.3 for Louisiana, and 9.8 for Georgia. Of the six states with the highest African American proportion, only Maryland (12.0) had more than 10 people per 10,000 homeless in 2017.

Thus it appears that homelessness is high among African Americans not so much because of where they reside, but mainly because their rates are very high relative to the rest of population in some areas in the North like New York and Los Angeles. This suggests that running regressions with the African American homeless rate as the dependent variable would be a valuable exercise (although CoCspecific racial homelessness rates are somewhat hard to come by). Many cross-section regressions have been run with the proportion of African Americans in the $\mathrm{CoC}$ population as an explanatory variable (it usually turns out insignificant, or close to it), but I'm not aware of any attempts to explain the geographic variation of African American homelessness, which is probably much greater than the geographic variation of total homelessness. Blinder-Oaxaca decompositions would also be interesting.

Since rates of illicit drug use, mental illness, and alcohol abuse do not appear to be higher among African Americans than other Americans, what can explain the greater propensity of poor African Americans to be homeless? As usual, I don't know.

\footnotetext{
${ }^{18}$ I estimate this from incidence data from New York City Department of Homeless Services (2017) assuming that spells and family sizes do not differ by race, and assuming that the racial composition of the unsheltered population was the same as that of the sheltered population. About 57 percent of the sheltered population was African American.
} 
The medical literature whites consistently have higher rates of mortality than blacks (Baggett et al. 2013; Hibbs et al. 1994; Hwang et al. 1998). ${ }^{19}$ Mechanically, this increases the proportion of blacks in the PIT count population. But this effect is necessarily small. This fact may indicate, however, that whites are able to maintain housing with fewer resources-physical and behavioral-than blacks. When whites become homeless, their health may be worse.

There are (at least) two promising candidate explanations for the over-representation. The first is incarceration. The proportion of African Americans in the population incarcerated for violent crimes is similar to the proportion of African Americans in the homeless population. Incarceration leads to employment and marriage difficulties (Mueller-Smith 2018), which could contribute to individual homelessness. Landlords may be unwilling to rent to ex-offenders, and federal housing programs present many barriers to people with criminal records (Geller and Curtis 2018).

The other candidate explanation is segregation. Even in the North, facilities for homeless people were segregated up until the 1960s (O'Flaherty 1996, 2014), and this fact, as well as fear of sleeping outside when Black people's security was not a major concern of police, probably kept the homelessness rate among blacks lower than the rate among whites in the Great Depression. Shelters and encampments provide less privacy than conventional housing, and so their residents live on more intimate terms with their neighbors than residents of conventional housing. When homelessness rose in major cities in the 1980s, much of the growth was among African Americans (O'Flaherty 1996), and so many shelters and encampments became predominantly black. This may be discouraging to whites. Schelling's model of segregation (1978) has no moving costs and no market prices, and so it may apply better to shelters than to conventional houses.

\footnotetext{
${ }^{19}$ I am grateful to Ann Elizabeth Montgomery for telling me about this.
} 
Neither of these explanations has been tested, and no other explanations have been tested either. This is another topic on which serious work should be done.

\section{Conclusion}

We don't know how to end homelessness. Not in the aggregate, anyway. We can't explain why homelessness in the two biggest American cities exploded in this decade, or why it fell in the rest of the country. We don't know why so many African Americans are homeless. We don't know how the harms of homelessness vary with time homeless or the conditions of homelessness-whether we should minimize entries at the expense of some longer stays, or whether living in a car is a worse experience than living in a shelter. And we know how only three policies-placements into subsidized apartments, prevention, and permanent supportive housing-affect aggregate homelessness. For the first two we know only about how the programs work in the atypical environment of New York City.

But we have learned a lot. The individual-level studies have shown that giving modest assistance to people who think they are about to become homeless is enough to keep a lot of them from becoming homeless, and that once people become homeless, any known intervention for returning a large number of them more quickly to conventional housing has to include a housing subsidy (interventions with only money have not been tried, and effective interventions that rely primarily on therapy have not been found yet). It used to be a serious contention that most homeless people were too sick to be housed, but it no longer is. On an aggregate level, weather, labor market conditions and housing prices affect homelessness, and maybe policies too, but modest changes in unemployment or rents cannot be expected to trigger huge changes in homelessness. No known policy reduces aggregate 
homelessness by one for every person successfully treated; for the most effective policies a handful or two of people have to be treated to reduce aggregate homelessness by one.

Together these results imply that making homeless policy should be an exercise in arranging subsidies in an environment where both moral hazard and adverse selection must be contended with. We didn't know this two decades ago (the view that homeless people had to be somehow made housing-ready was more popular then). Aggregate-level data sets that are available now can begin to tell us what policies do, and the individual-level data sets can begin to tell us how the policy effects matter to people. It's a good time for more economists to start working on homelessness.

\section{References}

Australian Bureau of Statistics. (2012). Census of Population and Housing: Estimating Homelessness, 2011. Catalogue number 2049.0.

Baggett, T. P., Hwang, S. W., O'Connell, J. J., Porneala, B. C., Stringfellow, E. J., Orav, E. J., Singer, D. E., \& Rigotti, N. A. (2013). Mortality among homeless adults in Boston: Shifts in causes of death over a 15-year period. JAMA Internal Medicine, 173(3), 189-195.

Buchanan, D., Kee, R., Sadowski, L.S., and Garcia, D. (2009). The health impact of supportive housing for HIV-positive homeless patients: A randomized controlled trial. American Journal of Public Health (99, sup. 3), S675-S680.

Byrne, T., Munley, E.A., Fargo, J.D., Montgomery, A.E., and Culhane, D.P. (2013). New perspectives on community-level determinants of homelessness. Journal of Urban Affairs 35(5), 607-25. 
Byrne, T., Fargo, J.D., Montgomery, A.E.,Munley, E.A., and Culhane, D.P. (2014). The relationship between community investment in permanent supportive housing and chronic homelessness. Social Service Review 88(2), 234-263.

Callahan et al., V. Carey et al. (1979). No. 79-42582, Supreme Court, New York County, Cot. 18, 1979.

Chiland, E. (2017). First project funded by Measure HHH gets underway: LA voters approved homeless housing bond last year. Curbed LA, December 20. Accessed on June 5, 2018 at https://la.curbed.com/2017/12/20/16801678/homeless-housing-path-metro-villas-hhh.

Coalition for Supportive Housing. (2015). Five NYC organizations become part of 'Moving On' initiative. December 28. Accessed on August 10, 2018 at https://www.csh.org/2015/12/five-nycorganizations-become-part-of-moving-on-initiative/

Cobb-Clark, D.A., Herault, N., Scutella, R., Tseng, Y-P. (2016). A Journey Home: What drives how long people are homeless? Journal of Urban Economics 91, 57-72.

Collinson, R. and D. Reed. (2018). The effects of evictions on low-income households. Working paper, New York University, Wagner School.

Community Action Network. (2017). Report of the Los Angeles Community Action Network: Proposition HHH First Year Performance Assessment. Los Angeles: The Network.

Corinth, K. (2017). The impact of permanent supportive housing on homeless populations. Journal of Housing Economics 35(1), 69-84.

--- and Lucas, D. (2018). When warm and cold don't mix: The implications of climate for the determinants of homelessness. Journal of Housing Economics 41(1): 45-56. 
Cragg, M., and O'Flaherty, B. (1999). Do homeless shelter conditions determine shelter population? The case of the Dinkins deluge. Journal of Urban Economics 46: 377-415.

Curtis, M., Corman, H., Noonan, K., and Reichman, N., (2010). Effects of child health on housing in the urban U.S. Social Science and Medicine 71(2), 2049-20156.

---, ----, ---, and ---. (2013). Life shocks and homelessness. Demography 50(6), 2227-2253.

Davis Farr, CPA. (2017). LAHSA: Financial Statements and Single Audit Report on Expenditures of Federal Awards, Fiscal Year Ended June 30, 2016. March 17. Accessed on June 4, 2018 at ????

De Blasio, B. (2017). Turning the Tide on Homelessness in New York City. New York.

Desmond, M. (2016). Evicted: Poverty and Profit in the American City. New York: Crown.

Diette, T.M., and Ribar, D. (2018). A longitudinal analysis of violence and housing insecurity. Economic Inquiry 56(3), 1602-1621.

District of Columbia. (2018). Human Services, Department of - Notice of Emergency and Proposed Rulemaking - Adding new Chapter 79, entitled "Flexible Rent Subsidy Pilot Program", of Title 29 of the District of Columbia Municipal Regulations, to establish standards to administer the District's Flexible Rent Subsidy Pilot Program and conditions of participation for enrolled households. Accessed on August 9, 2018 at https://www.dcregs.dc.gov/Common/NoticeDetail.aspx?Noticeld=N0068544

Doyle, J. (2008). Child protection and adult crime: Using investigator assignment to estimate causal effects of foster care. Journal of Political Economy 116(4), 746-770.

Early, D., and Olsen, E. (2002). Subsidized housing, emergency shelters, and homelessness: An empirical investigation using data from the 1990 census. The B.E. Journal of Economic Analysis 2(1): 136. 
Ellen, I.G. and O'Flaherty, B. (2010). Introduction. In Ellen, I.G., and O'Flaherty, B., eds. How to House the Homeless. New York: Russell Sage.

European Federation of National Organizations Working with the Homeless (FEANTSA). 2005. What is ETHOS? Accessed on 11 June 2018 at https://www.feantsa.org/download/ethos2484215748748239888.pdf

Flaming, D., and Burns, P. (2017). Who counts? Assessing accuracy of the homeless count. Los Angeles: Economic Roundtable. Accessed June 1, 2018 at https://papers.ssrn.com/sol3/papers.cfm?abstract id=3083255.

Freeman, R.B., and Hall, B. (1987). Permanent homelessness in America? Population Research and Policy Review 6, 3-27.

Gamer, E. (2018). Selected Initial Findings of the 2017 New York City Housing and Vacancy Survey. New York: New York City Department of Housing Preservation and Development.

Geller, A., and Curtis, M. (2018). One strike enforcement in public housing and housing security. Working paper, New York University and University of Wisconsin.

Goodman, S., Messeri, P., and O’Flaherty, B. (2014). How effective homelessness prevention impacts the length of shelter spells. Journal of Housing Economics 23(1): 55-62.

,--- ---, and ---. (2016). Homelessness prevention: On average, it works. Journal of Housing Economics 31(1):14-34.

Gubits, D., Shinn, M., Wood, M., Bell, S., Dastrup, S., Solari, C.D., Brown, S.R., Mclnnis, D., McCall, T., and Kattel, K. (2016) Family Options Study: 3-year Impacts of Housing and Services Interventions for Homeless Families. Washington, D.C.: U.S. Department of Housing and Urban 
Development, Office of Policy Development and Research. Accessed on June 12, 2018 at https://www.huduser.gov/portal/sites/default/files/pdf/Family-Options-Study-Full-Report.pdf

Herault, N. and Ribar, D. (2017). Food insecurity and homelessness in the Journeys Home survey. Journal of Housing Economics 37: 52-66.

Hibbs, J. R., Benner, L., Klugman, L., Spencer, R., Macchia, I., Mellinger, A., and Fife, D. (1994). Mortality in a cohort of homeless adults in Philadelphia. New England Journal of Medicine, 331(5), 304309.

Honig, M., and Filer, R. (1993). Causes of Intercity variation in homelessness. American Economic Review 83, 248-255.

Hwang, S. W., Lebow, J. M., Bierer, M. F., O'Connell, J. J., Orav, E. J., \& Brennan, T. A. (1998). Risk factors for death in homeless adults in Boston. Archives of Internal Medicine, 158(13), 1454-1460.

Johnson, G. and Scutella, R. (2018). Psychological distress and homeless duration. Housing Studies 33(3), 433-454.

Johnson, G. and Moschion, J. (2018). Homelessness and incarceration: A reciprocal relationship? Melbourne Institute of Applied Economics and Social Research, working paper.

Jorgenson, J. (2017). More homeless families denied at shelters after NYC toughens eligibility. New York Daily News. April 7.

---, ---, Tseng, Y-P, and Wood, G. (2015). Examining the relationship between structural factors, individual characteristics, and homelessness. Australian Housing and Urban Research Institute Positioning Paper series. 
Kertesz, S.G., and Johnson, G. (2017). Housing First: Lessons from the United States and Challenges for Australia. Australian Economic Review 50(2), 220-228.

Kirst, M., Zerger, S., Misir, V., Hwang, S., and Stergiopoulos, V., (2015). The impact of a Housing First randomized controlled trial on substance use problems among homeless individuals with mental illness. Drug and Alcohol Dependence (146), 24-29.

LAWT News Service. (2018). LA County makes 402 M investment in fight against homelessness; Year 2 Measure $\mathrm{H}$ spending plan funds expansion of housing outreach. May 17.

Lee, Moon Wha. (2013). Housing New York City 2011. New York: New York City Department of Housing Preservation and Development.

Lucas, D.S. (2017). The impact of federal homelessness funding on homelessness. Southern Economic Journal 84(2), 548-576.

Main, T. (2016). Homelessness in New York City: Policymaking from Koch to De Blasio. New York: New York University Press.

McClure, K. (2018). Length of stay in assisted housing. Cityscape 20(1), 11-38.

McVicar, D., Moschion, J., and Van Ours, J. (2015). From substance use to homelessness or vice versa. Social Science and Medicine (136-137), 89-98.

Montgomery, A.E., Fargo, J.D., and Byrne, T. (2015). Impact of community investment in safety net services on trajectories of unsheltered homelessness among veterans. Journal of Sociology and Social Welfare 42(4), 23-36.

Moschion, J. (2017). Do childhood experiences of parental separation lead to homelessness? Working paper, Melbourne Institute of Applied Economic and Social Research. 
Moulton, S. (2013). Does increased funding for homeless programs reduce chronic homelessness. Southern Economic Journal 79(3), 600-620.

Mueller-Smith, M. (2018). The criminal and labor market impacts of incarceration. American Economic Review ????

New York City. (2011). Mayor's Management Report, Fiscal 2011. New York: Mayor's Office of Management.

---. (2015). Mayor's Management Report, Fiscal 2015. New York: Mayor's Office of Management.

---. (2017). Mayor's Management Report, Fiscal 2017. New York: Mayor's Office of Management.

New York City Department of Homeless Services. (2017). DHS Data Dashboard-Fiscal Year to Date 2016, Population. Accessed April 9, 2017 at https://www1.nyc.gov/assets/dhs/downloads/pdf/dashboard/tables/populat-Tbls Dbd$\underline{03162016-Q 2 . p d f}$

---. (2018). Daily Report. Accessed on August 7, 2018 at https://www1.nyc.gov/assets/dhs/downloads/pdf/dailyreport.pdf.

New York State, Office of Temporary and Disability Assistance. (2015). Administrative Directive 15-ADM-06. September 15.

---. (2016). Administrative Directive 16-ADM-11. November 20.

O’Campo, P., Stergiopoulos, V., Nir, P., Levy, M., Misir, V., Chum, A., Arbach, B., Nisenbaum, R., To, M.J., and Hwang, S.W. (2016). How did a Housing First intervention improve health and social 
outcomes among homeless adults with mental illness in Toronto? Two-year outcomes with a randomized trial. BMJ Open (6), e10581.

O’Flaherty, B. (1996). Making Room: The Economics of Homelessness. Cambridge, MA: Harvard University Press.

---. (2003). Need and generosity: How markets for free goods equilibrate. Journal of Urban Economics 54(1), 157-172.

---. (2004). Wrong person and wrong place: For homelessness, the conjunction is what matters. Journal of Housing Economics 13 (1): 1-15.

---. (2009). When should homeless families get subsidized apartments? Journal of Housing Economics 18 (2), 69-80.

---. (2011). Homelessness in the United States. In: Brooks, N., Donaghy, K., and Knaap, G-J., editors. The Oxford Handbook of Urban Economics and Planning. New York: Oxford University Press. ---. (2012). Individual homelessness: Entries, exits, and policies. Journal of Housing Economics 21(2), 77-100.

---. (2014). Why are so many African Americans homeless? Talk, Social Equity Conference, University of Pittsburgh.

---, and Wu, T. (2006). Fewer subsidized exits and a recession: How New York City's family homeless shelter population became immense. Journal of Housing Economics 15 (2): 99-125.

---, and ---. (2008). Homeless shelters for single adults: Why does their population change? Social Service Review 82 (3): 511-550. 
---, Scutella, R., and Tseng, Y-P. (2018a). Using private information to predict homeless entries:

Evidence and prospects. Housing Policy Debate 28(3): 368-392.

---, ---, and ---. (2018b). Private information, exits from homelessness, and better ways to operate rehousing programs. Journal of Housing Economics 41(1), 93-105.

Olivet, J., Dones, M., Richard, M., Wilkey, C., Yampolskaya, S., Beit-Arie, M., and Joseph, L.. (2018). SPARC: Supporting Partnerships for Anti-Racist Communities: Phase One Study Findings. Center for Social Innovation, March.

Padgett, D.K., Henwood, B.F., and Tsemberis, S.J. (2016). Housing First: Ending Homelessness, Transforming Systems, and Changing Lives. New York: Oxford University Press.

Pittman, T.S. (2013). Department of Housing and Urban Development-Department of Veterans Affairs Supportive Housing HUD-VASH Program. May 13. Accessed on June 7, 2018 at http://www.nchv.org/images/uploads/Rapid\%20Lease-Up\%20and\%20Stabilization\%20of\%20HUDVASH.pdf.

Popov, I. (2016). Homeless programs and social insurance. Unpublished dissertation. Palo Alto, CA: Stanford University.

Quigley, J.M. (1990). Does rent control cause homelessness? Taking the claim seriously. Journal of Policy Analysis and Management 9, 89-93.

Raphael, S. (2010). Housing market regulation and homelessness. In Ellen, I.G., and O'Flaherty, B., eds. How to House the Homeless. New York: Russell Sage.

Rolston H, Geyer J, Locke G, Abt Associates (2013). Final Report: Evaluation of the Homebase Community Prevention Program. New York: Department of Homeless Services. 
Rosenheck, R. (2010). Service models and mental health problems: Cost-effectiveness and policy relevance. In Ellen, I.G., and O'Flaherty, B., eds. How to House the Homeless. New York: Russell Sage.

Scutella, R., Johnson, G., Moschion, J., Tseng, Y. \& Wooden M. (2012). “Journeys Home” Research Report 1, Report prepared for the Australian Government Department of Families, Housing, Community Services and Indigenous Affairs.

Seltman, H. (n.d.). Approximations for Mean and Variance of a Ratio. Carnegie Mellon University, Department of Statistics. Accessed May 20, 2018 at http://www.stat.cmu.edu/ hseltman/files/ratio.pdf

Sen, A. (2009). The Idea of Justice. Cambridge, MA: Harvard University Press.

Smith, D. (2018). Emergency shelters get a boost as LA County increases homeless spending by \$143 million. Los Angeles Times, May 15.

---, and Zhang, C. (2016). LA's homelessness math is a bit off-totals are the same but increases are smaller. Los Angeles Times, May 25.

Stergiopoulos, V., Hwang, S.W., Godzik, A., Nisenbaum, R., Latimer, E., Rabouin, D., Adair, C.E., Bourque, J., Connelly, J., Frankish, J., Katz, L., Mason, K., Misir, V., O’Brien, K., Sareen, J., Schutz, C.G., Singer, A., Streiner, D.L.., Vasiliadis, H.M., and Goering, P.N. (2015). Effect of scattered-site housing using rent supplements and intensive case management on housing stability among homeless adults with mental illness: A randomized trial. JAMA 313, 905-915.

Stuart, F. (2016). Down and out and under arrest: Policing and everyday life on skid row. Chicago: University of Chicago Press.

Swami, N. (2018). The effect of homelessness on employment entries and exits. Melbourne Institute of Applied Economics and Social Research, working paper 01/18. 
U.S. Department of Housing and Urban Development, Office of Community Planning and Development. (2007). The Annual Homeless Assessment Report to Congress: February 2007. Washington, D.C.

---. (2018). The Annual Homeless Assessment Report to Congress: 2017, part one. Washington, D.C.

U.S. Department of Veterans Affairs, National Center for Veterans Analysis and Statistics (2016). Veteran Population Projection Model 2016: Overview. Accessed 6 August 2018 at https://www.va.gov/vetdata/docs/Demographics/New Vetpop Model/Vetpop16 Overview.pdf

U.S. Interagency Council on Homelessness. (2017). Supportive Services. Accessed May 15, 2018 at https://www.usich.gov/solutions/housing/supportive-housing.

Wilde, E.T. (2012). Ten-year plans: A recent initiative to end homelessness in the US. Paper presented at APPAM National Conference, Baltimore, November 10.

Yi, K. (2018). Newark wants to guarantee a free lawyer for low-income tenants facing eviction. NJ. Com, May 2. Accessed June 15, 2018 at http://www.nj.com/essex/index.ssf/2018/05/right to counsel newark bill deblasio ras baraka.html

\section{Appendix: Robustness Checks on Veteran Results ${ }^{20}$}

Age structure. To the extent that I can correct for age structure, it appears to make no sizeable difference to the conclusions in the text. For 2010, we have no information on the ages of homeless veterans, but for 2011 AHAR has information both on all veterans who had shelter experience (an

\footnotetext{
${ }^{20}$ I thank Steve Metraux for raising these issues and sharing VetPOP documents and some correspondence on this subject.
} 
incidence measure), and for veterans who had long shelter stays. If we weight age groups in the ACS by their representation among all veterans with 2011 shelter experience, and multiply these weights by by the estimated change in ACS veteran population from 2010 to 2017 in the age group, then we estimate a 27.9 percent decrease in homeless veteran population if age-specific homelessness rates had remained constant. ${ }^{21}$

This procedure, however, puts too much on younger age groups because, relative to the PIT population, short-stayers are over-represented and short-stayers are on average younger than longstayers. Within the relevant veteran population, older age groups had larger population declines. An alternative weighting scheme uses the age distribution of long-stayers in the shelter population, and so probably over-estimates the contribution of demographic change. This procedure implies a 32.6 percent decrease in homeless veterans.

Since the PIT distribution is probably between the two age distributions I used (unless the distribution of PIT unsheltered population is considerably different from that of PIT sheltered population), this bounds the decrease in veteran homeless population with constant age-specific homelessness rates to between 27.9 percent and 32.6 percent. This gives me no reason to change the 30.4 percent decrease I used in the calculation in the text.

Alternative information on veteran population. The major challenge to the tentative conclusion in the text comes from an alternative to the ACS for counting veterans in the general population. Every few years, the National Center for Veterans Analysis and Statistics in the Department of Veterans Affairs publishes a 30-year projection of veteran population by age, gender, and location called VetPOP. The purpose is to guide the Department in developing services and siting facilities. It is a "bottom-up

\footnotetext{
${ }^{21}$ The ACS age categories for veterans are 18-34, 35-54, and 55-64. The AHAR categories are 18-29, 30-49, 50-61, and 62 and over. We assume no homeless people over 64, and use VetPOP data, described below, to translate ACS data to AHAR categories. VetPOP estimates veteran population in five-year age categories.
} 
projection": first it projects population in each county by modelling future discharges from the military, migrations, and deaths; and then It adds up the county projections to arrive at national totals. For each county, and a fortiori the nation, it uses and publishes a baseline population of veterans for the year before the projections start. For veterans under 65, it does not use ACS for the baseline, but for veterans over 65 (the majority) it does (U.S. Department of Veterans Affairs 2016).

Thus although VetPOP is not designed to produce optimal estimates at the national level, we can use it for alternative estimates of how the national veteran population was changing. In particular, VetPOP2011 uses 2010 as its baseline, and VetPOP2016 has 2016 and 2017 as the first two years it projects, and so the National Center should have fairly high confidence in its projections for those years. Following this simple approach, I find a 23.4 percent decrease in veteran population under 65 , between the 2010 baseline of VetPOP2011 and the 2017 second-year projection of VetPOP2016. This is noticeably lower than the ACS decrease in the ACS (with projection) and would imply a 35.7 percent decrease in veteran population if per capita veteran homelessness (per VetPOP) fell at the same rate as per capita national adult homelessness. That is still the overwhelming majority of the 46 percent decrease observed.

Is this credible and a better estimate than the ACS estimate? Since the ACS is designed to provide accurate national estimates and VetPOP is not, there do not seem to be strong reasons to favor VetPOP over ACS. VetPOP counts more veterans than the ACS does, apparently because some veterans do not say that they are veterans when the ACS asks them. VetPOP tries to estimate the number of people who should say that they are veterans, and the ACS tries to estimate the number of people who do say that they are veterans. Since AHAR data are based on the number of homeless people who say they are veterans, the correspondence with the ACS seems to be closer than the correspondence with VetPOP. But this is just preliminary and researchers should obviously experiment with both data sets. 
Figure 1

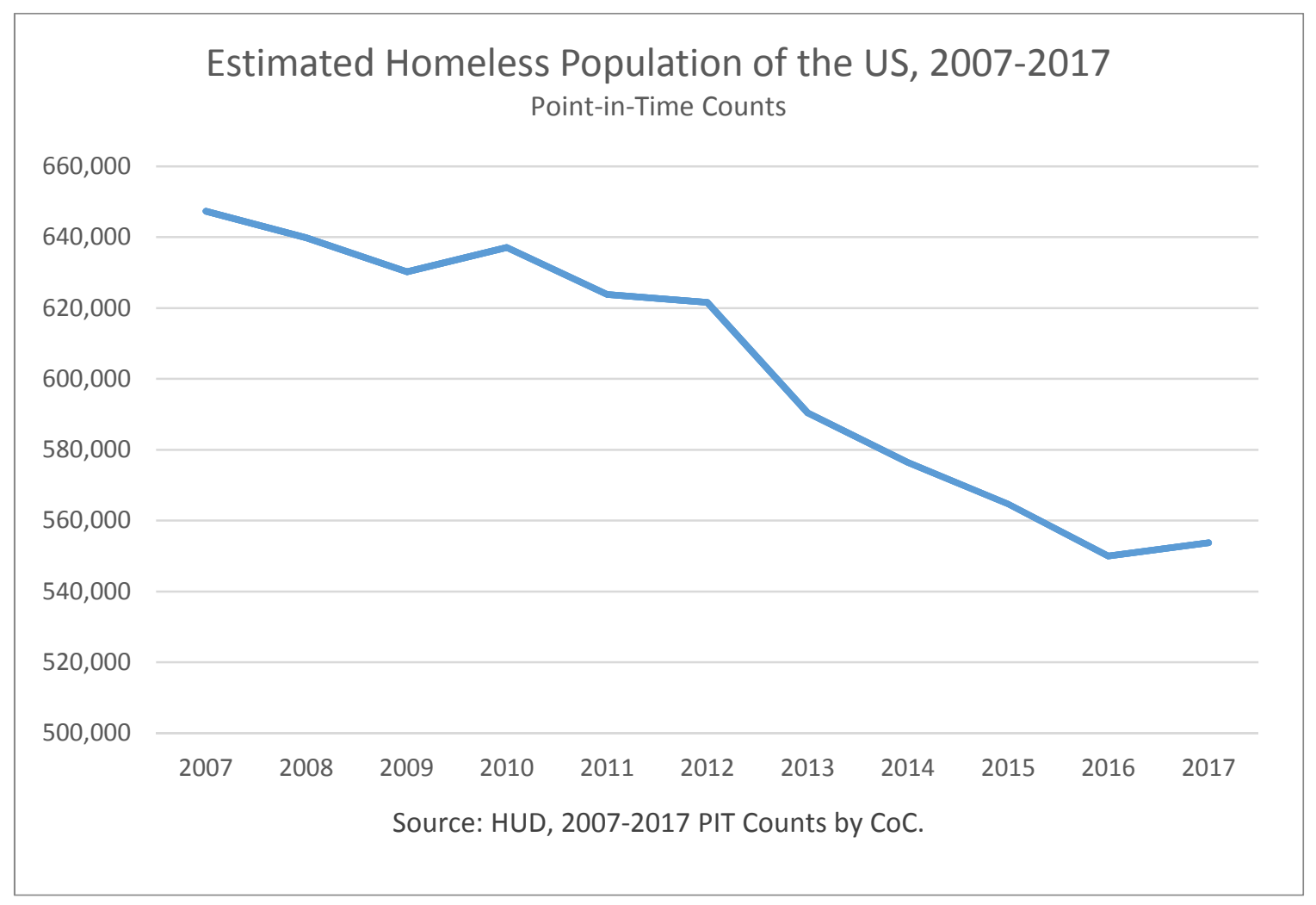


Figure 2

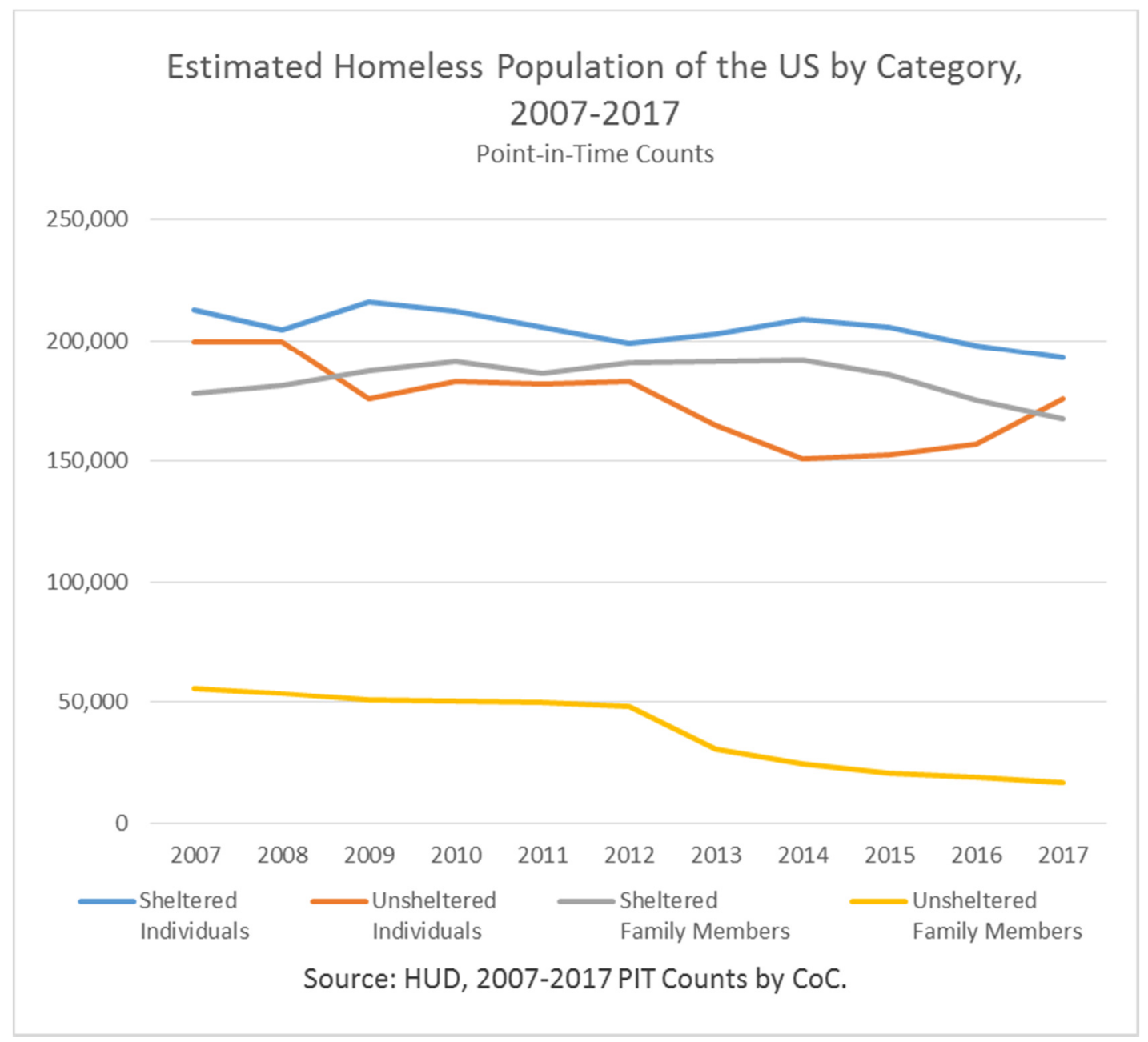


Figure $3 a 2010=100$ for all categories and locations

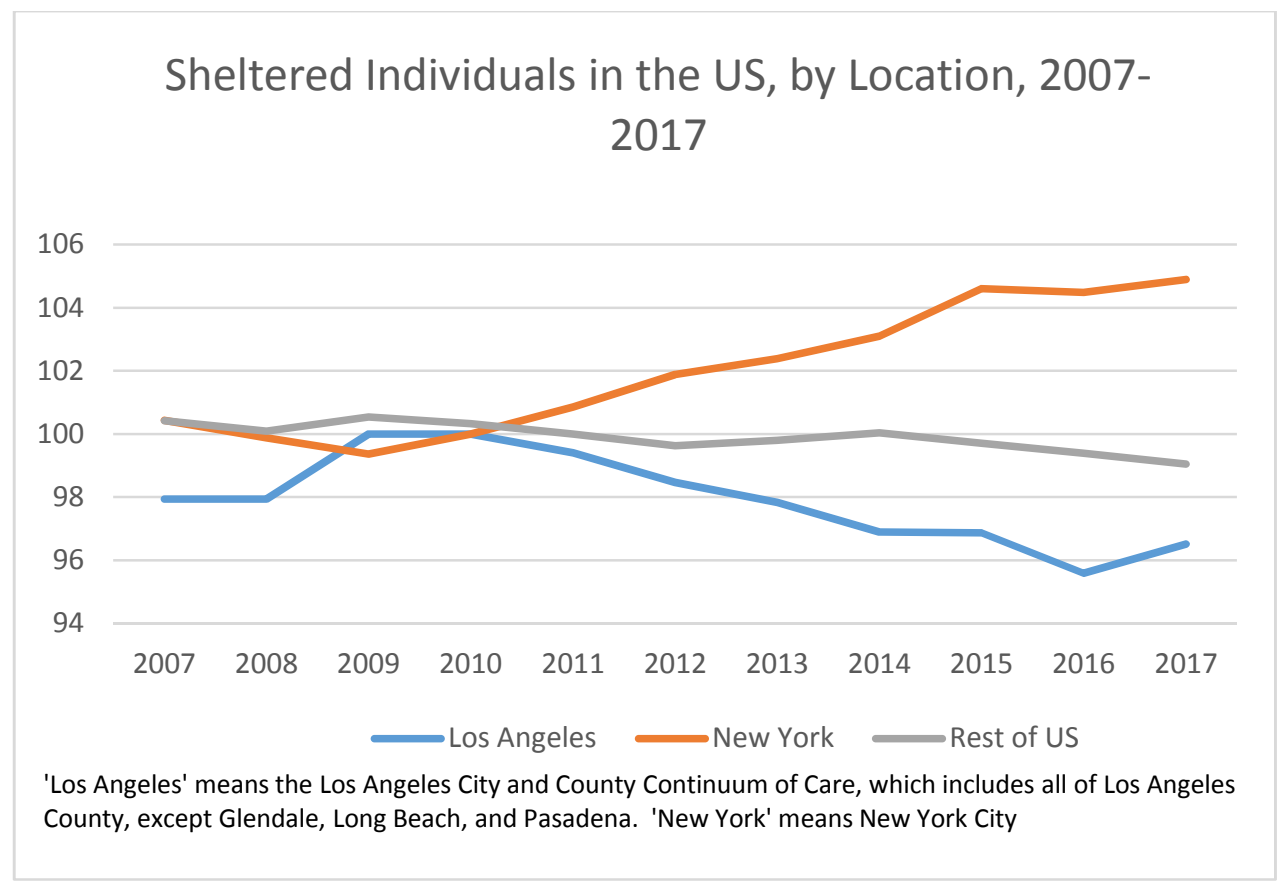


Figure $3 b$ 2010 $=100$

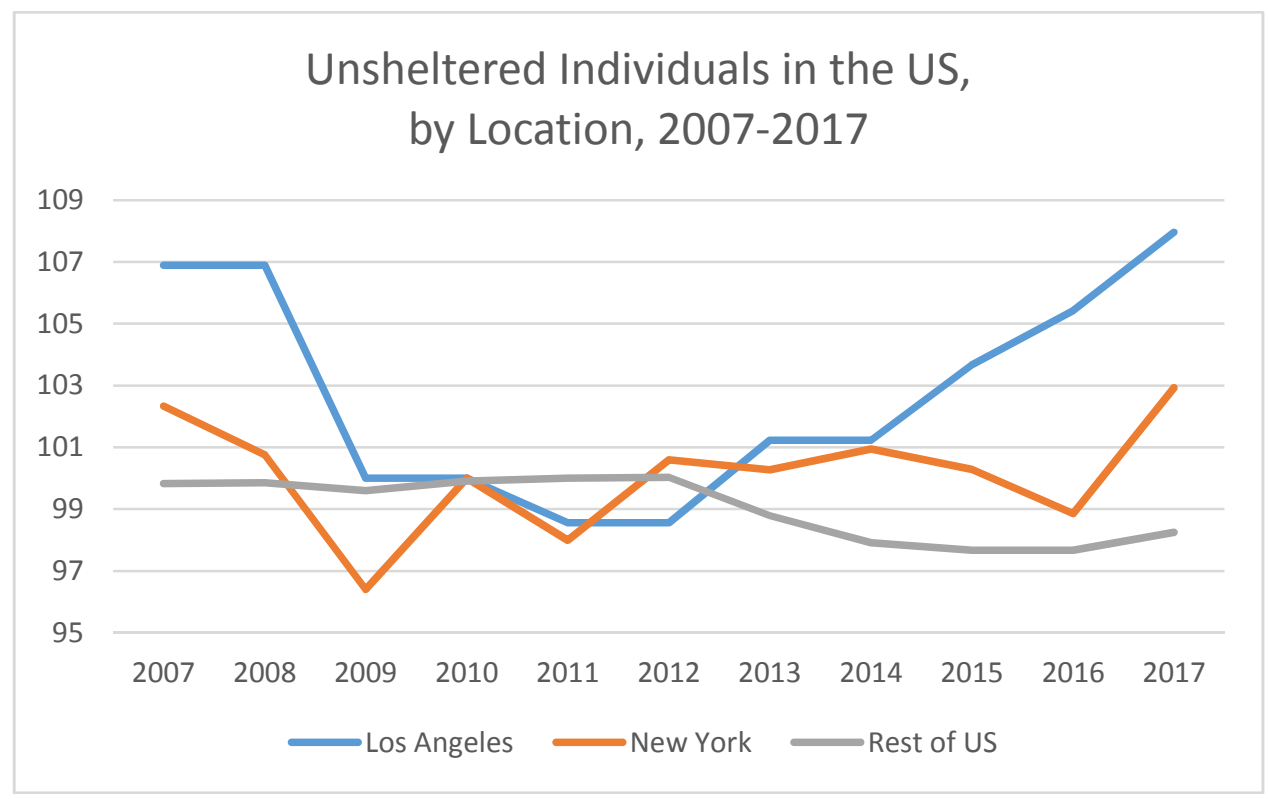


Figure 3c $2010=100$

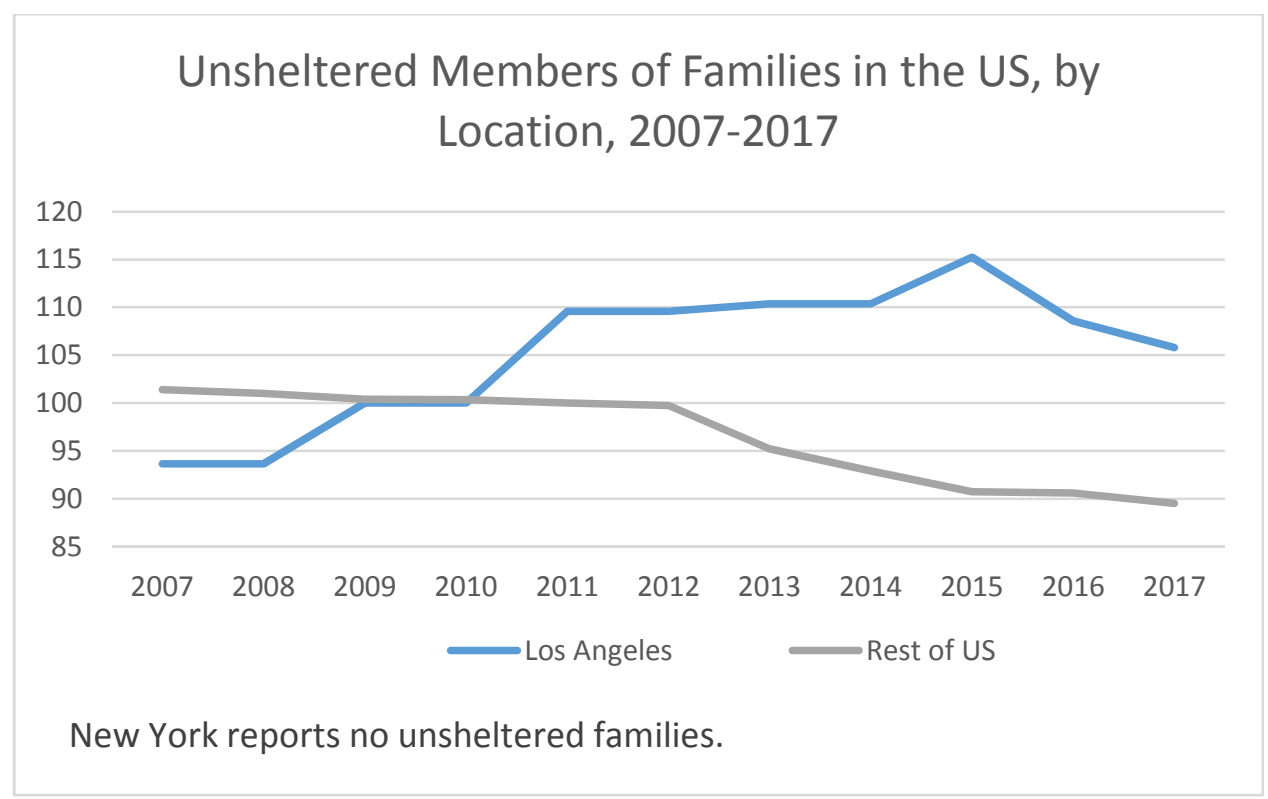




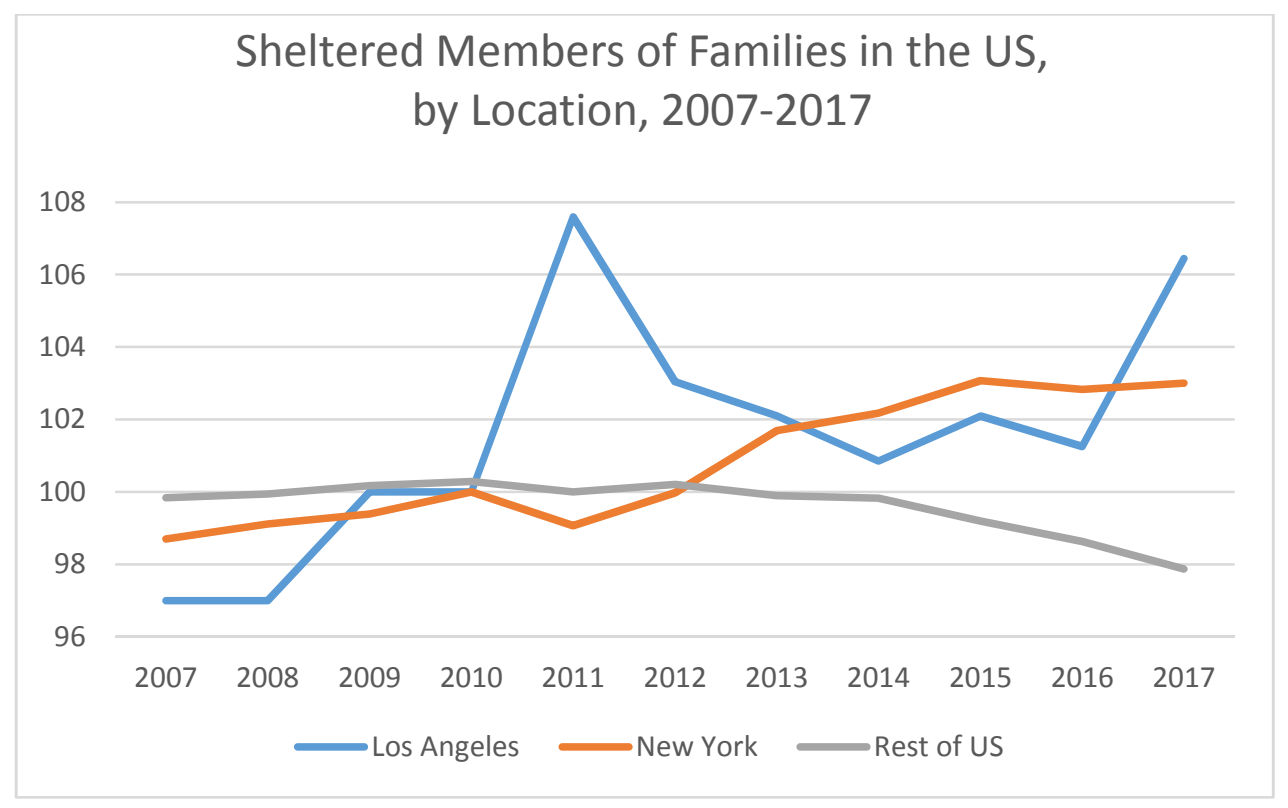




\section{Figure 4}

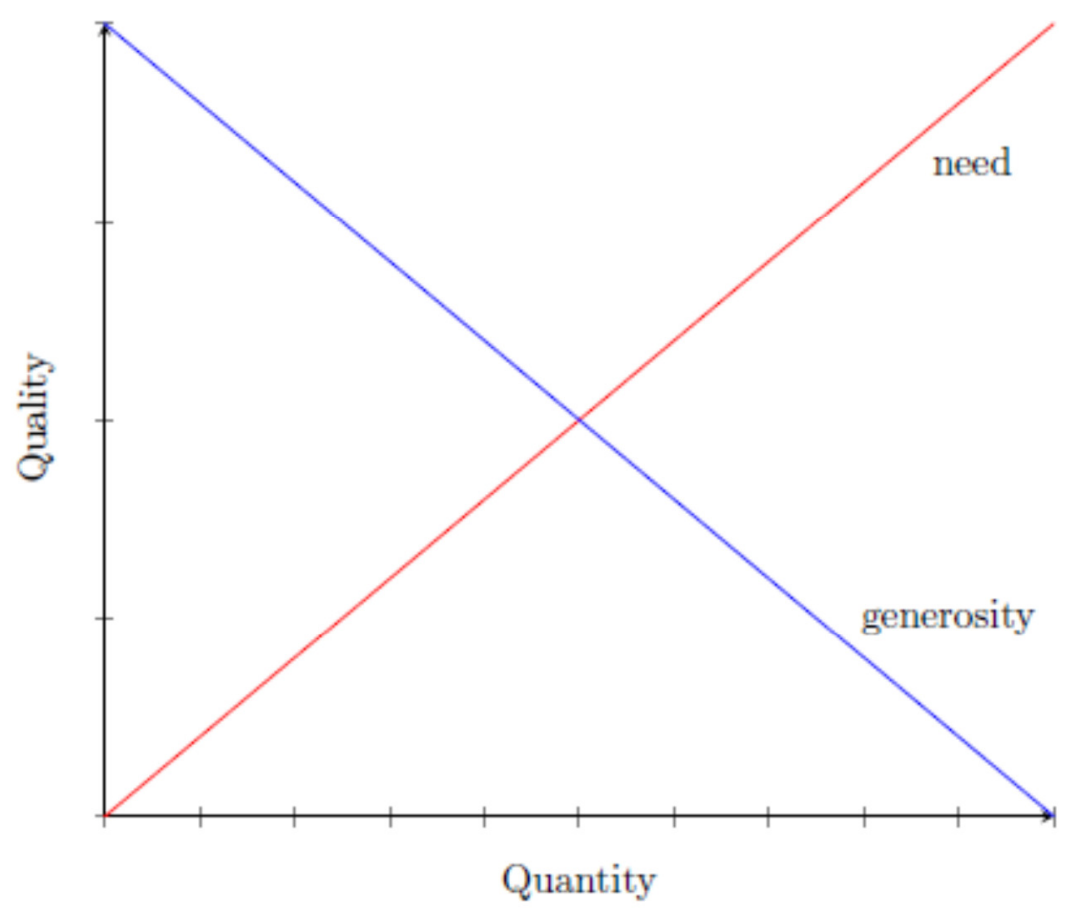

Figure 5

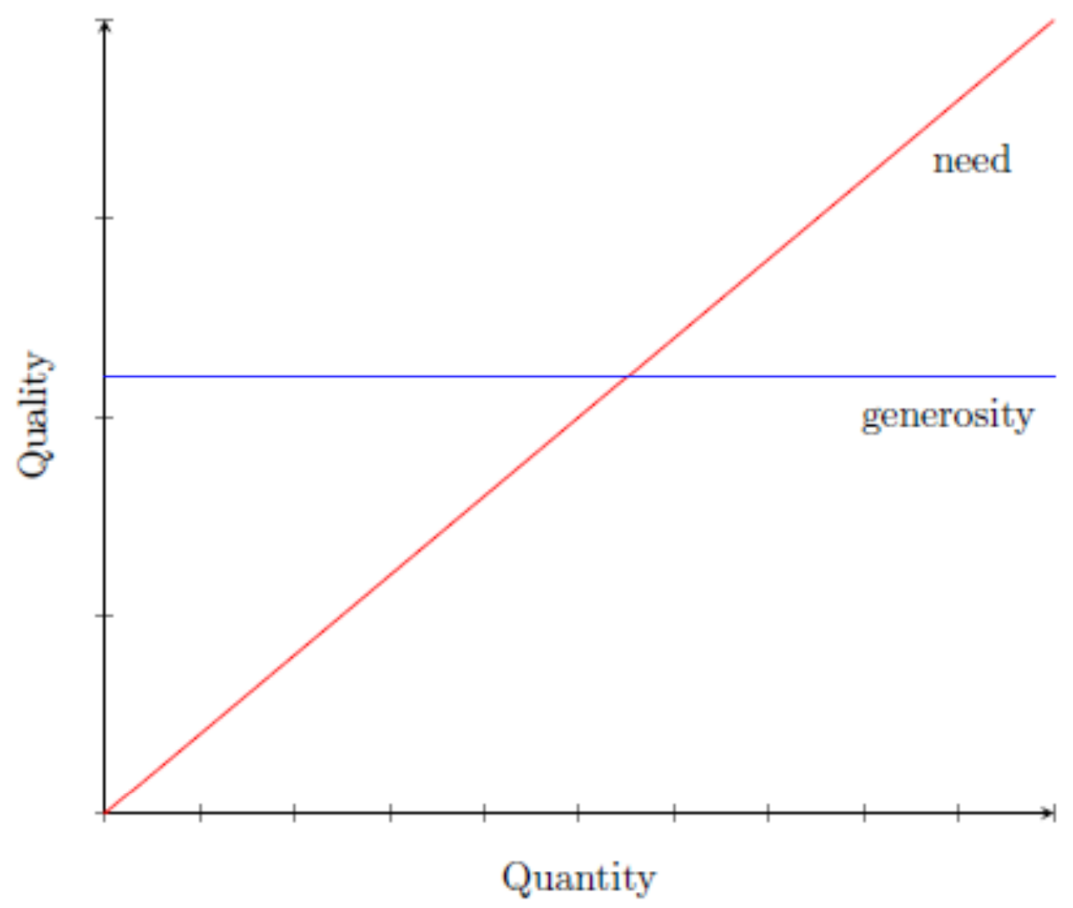




\section{Figure 6a}

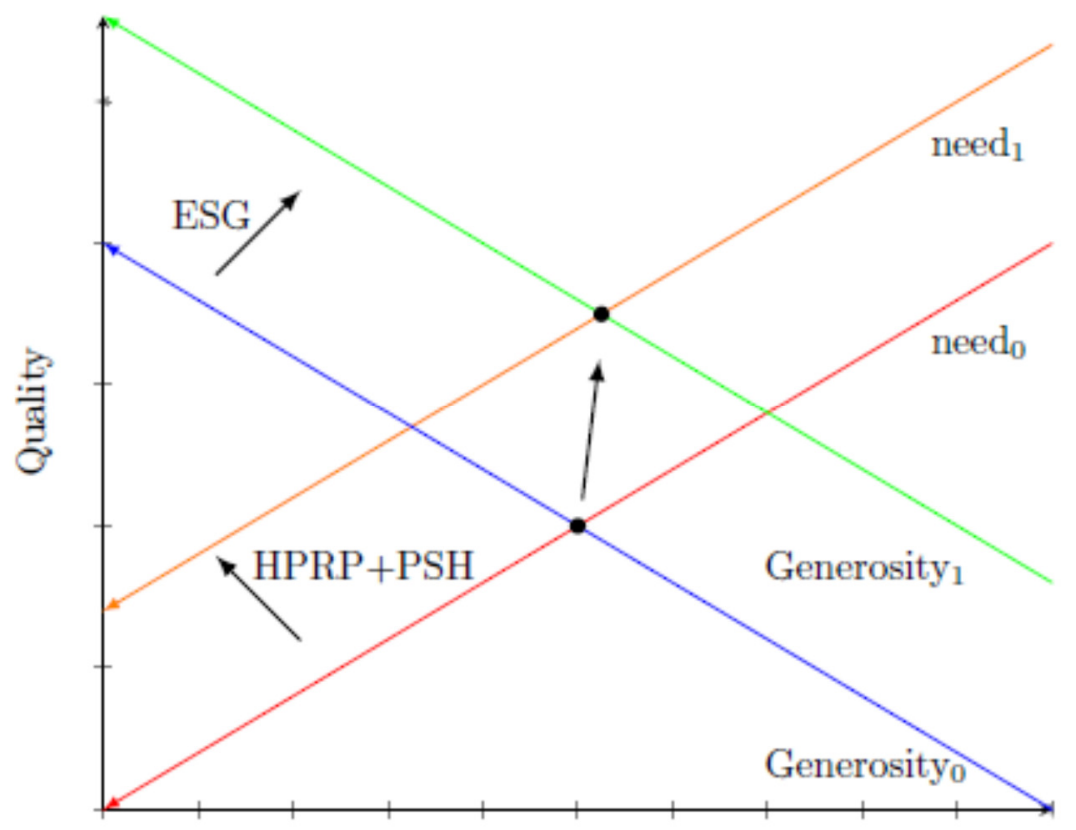

Quantity: Sheltered Individuals

\section{Figure 6b}

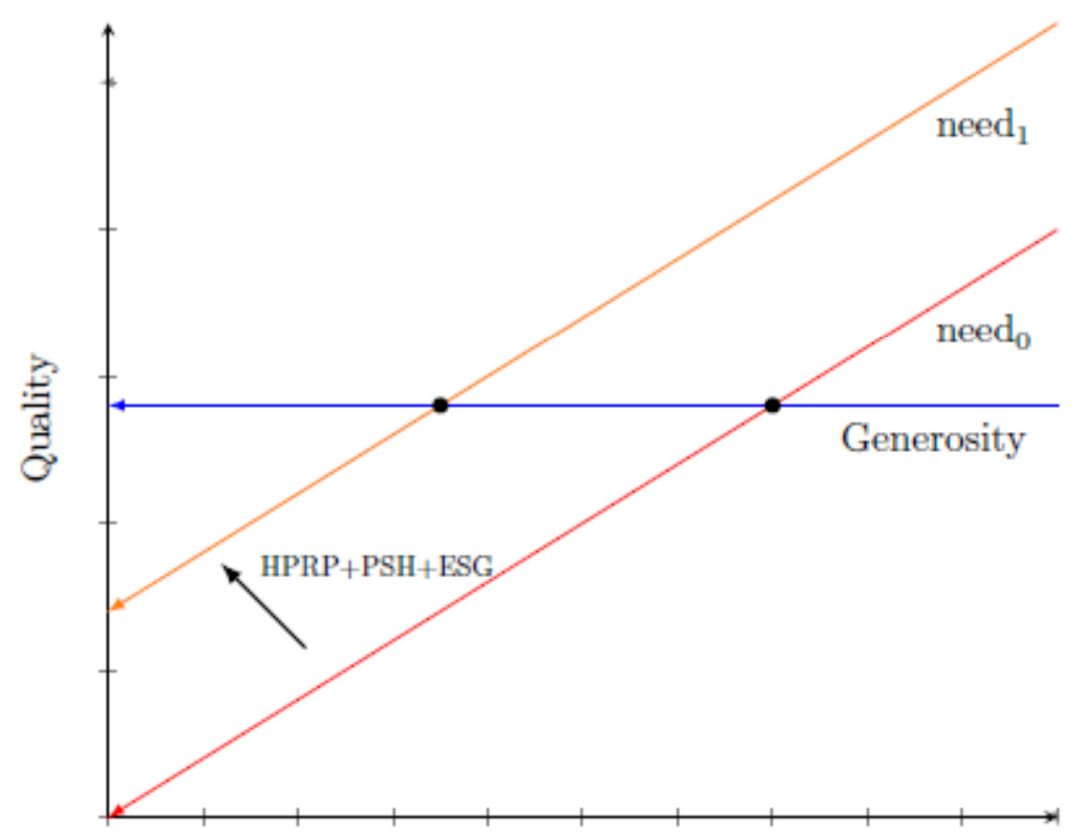

Quantity: Unsheltered Individuals 